\title{
SIGNIFICANCE OF SOLUBLE GROWTH FACTORS IN THE CHONDROGENIC RESPONSE OF HUMAN UMBILICAL CORD MATRIX STEM CELLS IN A POROUS THREE DIMENSIONAL SCAFFOLD
}

\author{
Remya S. Nirmal and Prabha D. Nair*
}

Division of Tissue Engineering and Regeneration Technologies, BMT Wing, Sree Chithra Tirunal Institute for Medical Sciences and Technology, Trivandrum.India

\begin{abstract}
Stem cell based tissue engineering has emerged as a promising strategy for articular cartilage regeneration. Foetal derived mesenchymal stem cells (MSCs) with their ease of availability, pluripotency and high expansion potential have been demonstrated to be an attractive cell source over adult MSCs. However, there is a need for optimisation of chondrogenic signals to direct the differentiation of these multipotent MSCs to chondrogenic lineage. In this study we have demonstrated the in vitro chondrogenesis of human umbilical cord matrix MSCs in three dimensional PVA-PCL (polyvinyl alcoholpolycaprolactone) scaffolds in the presence of the individual growth factors TGF $\beta 1$, TGF $\beta 3$, IGF, BMP2 and their combination with BMP2. Gene expression, histology and immunohistology were evaluated after $28 \mathrm{~d}$ culture. The induced cells showed the feature of chondrocytes in their morphology and expression of typical chondrogenic extracellular matrix molecules. Moreover, the real-time PCR assay has shown the expression of gene markers of chondrogenesis, SOX9, collagen type II and aggrecan. The expression of collagen type I and collagen type $\mathrm{X}$ was also evaluated. This study has demonstrated the successful chondrogenic induction of human umbilical cord MSCs in $3 \mathrm{D}$ scaffolds. Interestingly, the growth factor combination of TGF- $\beta 3$ and BMP-2 was found to be more effective for chondrogenesis as shown by the real-time PCR studies. The findings of this study suggest the importance of using growth factor combinations for successful chondrogenic differentiation of umbilical cord MSCs.
\end{abstract}

Keywords: Chondrogenesis; umbilical cord MSCs; cartilage tissue engineering; growth factors; threedimensional scaffolds.

*Address for correspondence:

Prabha D. Nair

Division of Tissue Engineering and Regeneration Technologies

BMT Wing

Sree Chithra Tirunal Institute for Medical Sciences and Technology

Trivandrum, 695012

India

Telephone Number: +91-471-2520242

FAX Number: +91-471-2341814

E-mail :pdnair49@gmail.com

\section{Introduction}

An ideal solution to repair or regenerate lost cartilage, has met with little success chiefly due to the complex structural and functional properties of articular cartilage (Temenoff and Mikos, 2000). Autologous chondrocyte implantation (ACI) and its modifications, intended for cartilage regeneration have shown clinical successes but with variable outcome. One of the concerns of chondrocyte transplantation is the limited availability of chondrocytes and their tendency to dedifferentiate with monolayer expansion (Stoddart et al., 2008). Recently, tissue engineering has emerged as a new paradigm for cell based therapies. Tissue engineering depends upon the interaction between cells, scaffolds and biochemical cues to create a biological tissue construct that functionally mimics the tissue of interest.

The concept of cartilage tissue engineering allows in vitro expansion of cells in a three-dimensional environment, with specific signalling molecules and other growth conditions and their transplantation to the defect site for the regeneration of damaged cartilage (Kuo et al., 2006). The limitations of obtaining autologous chondrocytes have paved the way for the researchers to view mesenchymal stem cells (MSCs), with their inherent property of self-renewal and multi-differentiation potential, as an alternate option. Adult mesenchymal stem cells sources, such as bone marrow-derived mesenchymal stem cells (BMSCs) adipose MSCs, synovial cells, etc., are excellent cell sources for cartilage regeneration and the chondrogenic ability of these cells are well documented (Tuan et al., 2003). However, the invasive methods for harvesting MSC and also their decrease in differentiation potential due to aging and disease have spurred a quest for a new cell source.

Human umbilical cord mesenchymal stem cells (hUCMSCs), the cells that are recovered postnatally from umbilical cord, a discarded clinical waste, forms a relatively new stem cell source that have multi differentiation potential and are capable of differentiating, in vitro and in vivo, into adipogenic, chondrogenic, osteogenic as well as neural and cardiomyogenic lineages (Wang et al., 2004). The inherent immunoregulatory and immunomodulatory properties of hUCMSCs, along with their high expansion potential and the added advantage of a non-invasive collection procedure have made them an excellent allogenic cell source for stem cell-based therapies (Hartmann et al., 2009; Tipnis et al., 2010).

Three dimensional scaffolds in tissue engineering serve as a platform for complex cell-cell and cellmatrix interactions and mimic the properties of native 
extracellular matrix (Langer and Tirrell, 2004). The functionality of cartilage is mainly attributed by the highly specialised extracellular matrix (ECM) components elaborated by the resident chondrocytes. The collagen fibres provide tensile strength to cartilage, while the large proteoglycans entrapped in the fibrillar network, with its high water holding capacity, helps to resist the compression experienced at the joints during normal physiological activities (Sophia Fox et al., 2009). Several natural and synthetic scaffolds, such as gelatin, alginate, silk, PCL, PLLA, agarose gels, hyaluronate gels etc., have been used for evaluating chondrogenesis for cartilage tissue engineering applications (Csaki et al., 2008). Our lab has fabricated a synthetic semi-interpenetrating network (IPN) scaffold of polyvinyl alcohol and polycaprolactone (PVA-PCL) and demonstrated its inherent physicochemical properties of favouring chondrogenesis with chondrocytes as well as with bone marrow mesenchymal stem cells (Mohan and Nair, 2010). The polymers in the semiIPN synthetic scaffold mimic the properties of collagen and glycosaminoglycans present in native cartilage. Its appropriate swelling and pore structure enabled cell-cell and cell-matrix interactions promoting better chondrogenesis and enhanced secretion of extracellular matrix components (Mohan and Nair, 2008). In addition to the scaffold characteristics, microenvironment also plays a pivotal role in chondrogenesis. Mesenchymal stem cells have been shown to undergo chondrogenic induction in the presence of chondrogenic growth factors. These growth factors, particularly members belonging to transforming growth factor beta super family, induce MSCs to acquire a chondrogenic phenotype which is characterised by increased expression of genes responsible for the synthesis of chondrocyte-specific extracellular matrix molecules such as collagen type II and aggrecan. They also lose their characteristic morphology and take a spherical shape resembling chondroblasts (Heng et al., 2004).

Earlier studies on hUCMSC chondrogenesis focused on the use of high density pellet cultures (Wang et al., 2009). Recently, there are a few studies on chondrogenesis of hUCMSCs in PGA/PLA based scaffolds and nanofibrous collagen PCL scaffolds by different chondrogenic growth factors (Zhao and Detamore, 2010; Fong et al., 2010). The degree of chondrogenesis may vary with different growth factors and their concentrations used for the differentiation process. In the natural milieu, chondrogenesis, i.e. differentiation of stem cells to chondrocyte phenotype with the elaboration of specific extracellular matrix components, is governed by a conjunction of several growth factors. However, in the in vitro conditions, the optimisation of signals and conditions promoting chondrogenesis as well as the molecular mechanisms that control the differentiation of hUCMSC are still not fully understood. This study evaluates the effect of soluble growth factors in the chondrogenesis of human umbilical cord mesenchymal stem cells in PVA-PCL scaffolds so as to identify the appropriate combination of soluble growth factors that can promote umbilical cord matrix mesenchymal stem cell differentiation to chondrocytes.

\section{Materials and Methods}

\section{Materials}

Collagenase type 2, hyaluronidase, ascorbate phosphate, dexamethasone, indomethacin, Oil red O, betaglycerophosphate, Alizarin red and triton X (SigmaAldrich, St. Louis, MO, USA). dispase (BD Biosciences, Mississauga, Canada). Dulbecco's modified Eagle medium - high glucose (DMEM HG), DMEM - low glucose (DMEM-LG), DMEM-Hams F12, foetal bovine serum (FBS), antibiotic-antimycotic (AB/AM) solution, $0.25 \%$ trypsin EDTA and L-glutamine (Gibco, Oklahoma City, OK, USA). FITC-phallodin (Molecular Probes, Eugene, OR, USA), mouse anti-human monoclonal antibodies vimentin, CD45, CD90, CD44, CD105, CD34 and CD29 and FITC/PE-conjugated chicken anti-mouse antibody (Santacruz, Dallas, TX, U.S.A). Paraformaldehyde (SD Fine, Mumbai, India).

\section{Isolation of mesenchymal stem cells from umbilical cord Wharton's jelly}

Fresh human umbilical cords were obtained from caesarean cases (after approval from the hospital IEC and with informed consent) and stored in phosphate buffered saline (PBS) for 1 to $24 \mathrm{~h}$ before processing the tissue to obtain mesenchymal cells. After removal of blood vessels, the cord was cut into smaller pieces and treated with an enzyme cocktail consisting of $0.2 \% \mathrm{w} / \mathrm{v}$ collagenase type $2,0.15 \% \mathrm{w} / \mathrm{v}$ hyaluronidase and dispase for $2 \mathrm{~h}$ at $37{ }^{\circ} \mathrm{C}$, with agitation. The homogenous solution was then centrifuged at $1800 \mathrm{rpm}$ for $10 \mathrm{~min}$ at $4{ }^{\circ} \mathrm{C}$ to form a pellet. The pelleted cells were suspended and cultured in DMEM-F12 supplemented with $10 \%$ foetal bovine serum and $1 \%$ penicillin/streptomycin in $5 \% \mathrm{CO}_{2}$ atmosphere in a $37^{\circ} \mathrm{C}$ incubator. Non-adherent cells were removed by initial medium change after $24 \mathrm{~h}$. Thereafter medium was changed every 3-4 d.

\section{Characterisation of mesenchymal stem cells}

The isolated cells were screened by immunocytochemistry (ICC), flow cytometry and PCR analysis as per established protocol. ICC was used to screen for cell specific markers vimentin, CD90, CD44 and CD105. Briefly, cells grown on cover slips were fixed in $4 \%$ paraformaldehyde for $20 \mathrm{~min}$, permeabilised by incubation with $50 \%$ chilled methanol for $20 \mathrm{~min}$ at room temperature, and washed three times in PBS. They were blocked with $2 \%$ bovine serum albumin (BSA) for $30 \mathrm{~min}$, and then incubated for a further $60 \mathrm{~min}$ with the following primary antibodies: vimentin, CD90 and CD105 (1:100 dilutions in 0.5\% BSA). The cells were then washed in PBS and incubated with 1:100 dilution of secondary antibody for $1 \mathrm{~h}$, and washed again three times in PBS. The labelled samples were mounted on glass slides, and viewed under fluorescent microscopy. Flow cytometric analysis to quantify cell surface markers was done for CD44, 90, 105, 29, 34 and 45. Briefly, trypsinised cells suspended in PBS at a concentration of $1 \times 10^{6}$ cells/ $\mathrm{mL}$, were washed twice with PBS and incubated with fluorescein isothiocyanate (FITC)-conjugated antibodies against CD45, CD90, CD44 and phycoerythrin (PE)conjugated antibodies against CD105, CD34, and CD29 in 
the dark for $30 \mathrm{~min}$ at $4{ }^{\circ} \mathrm{C}$. All analyses were standardised against negative control (cells alone). After incubation, the cells were washed with PBS and centrifuged to remove any unbound antibodies, resuspended in PBS and analysed by flow cytometry (FACS Aria; BD Biosciences). PCR analysis was done to demonstrate the pluripotency markers Oct 4 and Nanog.

\section{Multidifferentiation potential of hUCMSC}

To demonstrate the multipotency of isolated hUCMSC, the cells were induced to differentiate into adipocytes and osteoblasts following standard protocols (Baksh et al., 2007). Briefly, for osteogenic differentiation, the cells were cultured in osteogenic differentiation medium, containing DMEM-LG, supplemented with $10 \%(\mathrm{v} / \mathrm{v})$ FBS, 2 mM L-glutamine, $100 \mathrm{nM}$ dexamethasone, $10 \mathrm{mM} \beta$-glycerophosphate and $0.2 \mathrm{mM}$ L-ascorbate for $21 \mathrm{~d}$. Osteogenic differentiation was analysed by demonstration of $\mathrm{Ca}$ mineralisation by Alizarin red staining. Adipogenic differentiation was induced by culturing the cells in adipogenic medium consisting of DMEM-LG supplemented with $10 \%$ (v/v) FBS, 2 mM L-glutamine, $50 \mu \mathrm{g} / \mathrm{mL}$ of ascorbate- 1 phosphate, $100 \mathrm{nM}$ dexamethasone and $50 \mu \mathrm{g} / \mathrm{mL}$ indomethacin for $21 \mathrm{~d}$. After culture, adipogenic differentiation was demonstrated by Oil Red O staining of lipid granules.

\section{Fabrication of PVA-PCL scaffolds}

Polyvinyl alcohol-polycaprolactone semi-interpenetrating polymer network (IPN) scaffolds for the study were prepared as per the established protocol (Mohan and Nair, 2008). Briefly, the scaffold was fabricated by mixing (3000 rpm) polyvinyl alcohol (aqueous solution) and polycaprolactone (in chloroform) at equal concentrations using a mechanical stirrer to form a homogeneous foam. The foam was immediately transferred to moulds, frozen, and lyophilised at $-80{ }^{\circ} \mathrm{C}$ for $24 \mathrm{~h}$. The porous scaffolds were cross-linked with $1 \%$ glutaraldehyde solution to form the semi-interpenetrating network, washed to remove traces of glutaraldehyde and lyophilised before use. The lyophilised scaffolds were cut into discs of desired size, sterilised by ethylene oxide and stored till use. The scaffolds were physicochemically characterised to demonstrate their porous structure, swelling ability, chemical composition and biodegradation profile using various techniques, as reported in our earlier studies (Mohan and Nair, 2008).

\section{Chondrogenic differentiation of hUCMSC on 3D PVA-PCL scaffolds}

PVA-PCL scaffolds ( $3 \mathrm{~mm}$ diameter and $2 \mathrm{~mm}$ thickness) were seeded at a density of $5 \times 10^{5}$ cells/scaffold and cultured in DMEM supplemented by $10 \%$ FBS and $1 \mathrm{x}$ $\mathrm{AB} / \mathrm{AM}$. Briefly, the trypsinised cells of passage 3-4 were suspended in $100 \mu \mathrm{L}$ medium and were dropped slowly onto both sides of PVA-PCL scaffold in a polypropylene vial using a micropipette. The seeding volume was optimised by testing the medium uptake ability of the scaffolds prior to seeding. The wicking action of the PVA-PCL scaffold sucked in all the fluid dropped onto it, and the appropriate swelling property of the scaffold helped in retaining the medium as well as the cells inside the porous structure.
The cell-seeded constructs were kept undisturbed at $37^{\circ} \mathrm{C}$ in a $\mathrm{CO}_{2}$ incubator for 2-4 h to facilitate attachment of the cells after which appropriate amount of medium was fed slowly through the sides of the tube. After $24 \mathrm{~h}$ of culture, the medium was replaced by chondrogenic medium containing respective growth factors. Chondrogenic medium consisted of DMEM without FBS, 1x AB/AM, $40 \mu \mathrm{M}$ proline, $50 \mu \mathrm{M}$ ascorbic acid, $1 \%$ non-essential amino acids (NEAA), $1 \%$ insulin-transferrin-selenium (ITS) and $10^{-7} \mathrm{M}$ dexamethasone. The constructs were grown in different growth factor conditions supplemented with recombinant human transforming growth factor $\beta 1$ (TGF $\beta 1,10 \mathrm{ng} / \mathrm{mL}$ ), transforming growth factor $\beta 3$ (TGF $\beta 3,10 \mathrm{ng} / \mathrm{mL}$ ), insulin-like growth factor (IGF, $10 \mathrm{ng} / \mathrm{mL}$ ), bone morphogenic protein (BMP2, $25 \mathrm{ng} / \mathrm{mL}$ ), TGF $\beta 1+B M P 2(10 \mathrm{ng} / \mathrm{mL}, 25 \mathrm{ng} / \mathrm{mL})$, TGF $\beta 3+\mathrm{BMP} 2$ $(10 \mathrm{ng} / \mathrm{mL}, 25 \mathrm{ng} / \mathrm{mL})$, IGF+BMP2 $(10 \mathrm{ng} / \mathrm{mL}, 25 \mathrm{ng} / \mathrm{mL})$ and control without any growth factors, respectively. The constructs were maintained at $37^{\circ} \mathrm{C}$ and $5 \% \mathrm{CO}_{2}$ for $28 \mathrm{~d}$. Medium was replaced every $3 \mathrm{~d}$. For IGF-supplemented constructs, instead of ITS only selenium $(5 \mathrm{ng} / \mathrm{mL})$ and transferrin $(5.5 \mu \mathrm{g} / \mathrm{mL})$ was used.

\section{Analysis of cultured constructs Cell viability}

The viability of cells in the scaffold after culture was determined using LIVE/DEAD ${ }^{\circledR}$ viability/cytotoxicity kit (Molecular Probes). Briefly, the cell-seeded constructs were incubated in DMEM containing $4 \mathrm{mM}$ calcein AM and $2 \mathrm{mM}$ ethidium bromide-homodimer for $30 \mathrm{~min}$. Imaging was done using a Zeiss 510 Meta confocal microscope (excitation of calcein at $495 \mathrm{~nm}$ using an argon laser and ethidium bromide at $528 \mathrm{~nm}$ using a HeNe laser).

\section{SEM analysis}

SEM analysis of the cell-seeded constructs was done after culture. The samples were washed in PBS and fixed in $2.5 \%$ glutaraldehyde overnight at $4{ }^{\circ} \mathrm{C}$, dehydrated using graded acetone changes, critical point dried, gold sputtered in vacuum, and examined by scanning electron microscopy (JEOL-GSM6390, LV, Tokyo, Japan).

\section{Biochemical analysis}

Biochemical analysis was done to quantify the deposition of s-GAGs as an indicator of chondrogenesis, according to the established protocol (Farndale et al., 1986). Briefly, the cell-seeded constructs were digested with papain $(1.8 \mathrm{mg} /$ $\mathrm{mL}$, Sigma) at $65^{\circ} \mathrm{C}$ for $16 \mathrm{~h}$ and total $\mathrm{GAG}$ content from the supernatant was measured at $525 \mathrm{~nm}$ following binding with DMMB (dimethyl methylene blue) dye. Total DNA from the supernatant was also quantitated by picogreen assay. The results were represented graphically. Three samples were used for each of the quantitative experiments. Each parameter was expressed as mean with standard deviations.

\section{Histology and immunohistochemistry}

The constructs were processed for histological analysis following dehydration, paraffin embedding and staining as per the standard protocol. GAG deposition was demonstrated by safranin $\mathrm{O}$ staining. Immunohistochemical 
analysis was done to demonstrate the chondrogenic marker collagen type 2 . The paraffin sections were treated with trypsin for antigen retrieval and incubated with monoclonal Col2a1 antibody (Sanatcruz) 1:50 dilution and visualised using Ultra Tech HRP (DAB) Streptavidin-Biotin Universal detection system (Beckman Coulter, Mumbai, India). The sections were, dehydrated, mounted and imaged by microscopy.

\section{Gene expression using RT-PCR}

Total RNA was isolated using Trizol reagent (Invitrogen, Carlsbad, CA, USA) protocol according to the manufacturer's instructions and the yield and purity was determined using a NanoDrop ${ }^{\circledR}$ ND-1000 UV-Vis Spectrophotometer. The first-strand cDNA was then synthesised from total RNA; $1 \mu \mathrm{L}$ Revert Aid H Minus M-MuLV reverse transcriptase $(200 \mathrm{U} / \mu \mathrm{L}), 4 \mu \mathrm{L}$ reaction buffer $(5 \mathrm{x}), 0.5 \mu \mathrm{L}$ Ribo lock RNase inhibitor (40 U/ $\mu \mathrm{L}), 1 \mu \mathrm{L}$ oligo $(\mathrm{dT})$ primer $(0.5 \mu \mathrm{g} / \mu \mathrm{L})$ and $2 \mu \mathrm{L} \mathrm{dNTP}$ mix $(10 \mathrm{mM})$ (Fermentas, Mumbai, India) for a $20 \mu \mathrm{L}$ reaction volume reverse transcription (RT) reaction using the Thermal Cycler (Master Cycler; Eppendorf India Limited, New Delhi, India). The real-time PCR was performed using a Chromo4 system (Bio-Rad, Hercules CA, USA). All reactions were carried out in a total volume of $25 \mu \mathrm{L}$, containing $12.5 \mu \mathrm{L}$ qPCR SYBR Green master mix (Fermentas), $7.5 \mu \mathrm{L}$ DEPC water, $1 \mu \mathrm{L}$ forward and $1 \mu \mathrm{L}$ reverse primer $(10 \mu \mathrm{M})$ (Integrated DNA Technologies, Coralville, IA, USA), and $3 \mu \mathrm{L}$ cDNA over
40 cycles. The details of primer sequences are listed in Table 1. For each gene, the quality and specificity were assessed by examining PCR melt curves after real-time PCR. Glyceraldehyde phosphate dehydrogenase was used as the house keeping gene. The relative level of expression with respect to control was calculated with the following formula: relative expression ratio of the gene of interest $=2-\Delta \Delta \mathrm{CT}$, where $\Delta \Delta \mathrm{CT}=\Delta \mathrm{CT}$ gene of interest in growth factor supplemented conditions - $\Delta \mathrm{CT}$ gene of interest in control (without growth factor). $\Delta \mathrm{CT}=\mathrm{Ct}$ gene of interest $-\mathrm{Ct}$ house keeping gene (Dussault and Pouliot, 2006).

\section{Statistics}

For the experiments on chondrogenic differentiation by growth factor treatment, pooled cells enumerated from umbilical cords of 6 donors were used. There were 3 cellseeded constructs per treatment group for all the various analyses performed and the data presented here is that of 3 independent experiments. For all experiments, statistical significance of differences between groups was determined using $t$-test for two treatments and one-way ANOVA for more than two treatments with the Tukey post hoc test in VassarStats: Website for Statistical Computation. Any reference to a difference in the Results and Discussion sections implies statistical significance at the level $p<0.05$ except otherwise mentioned. In all cases, where the difference was significant, symbols are used to indicate the difference and explained in the figure captions.

Table 1. Primer details.

\begin{tabular}{|c|c|c|c|c|}
\hline No & Genes & Primer Sequences. & Accession No & Base pair (Bp) \\
\hline 1 & Nanog & $\begin{array}{l}\text { F-GATGCCTGGTGAACCCGACT } \\
\text { R-GGCCTTCCCCAGCAGCTTCC }\end{array}$ & NM024865.2 & 262 \\
\hline 2 & Oct 4 & $\begin{array}{l}\text { F-GGGGATGGCGTACTGTGGGC } \\
\text { R-GTGGCTGATCTGCTGCAGTGT }\end{array}$ & NM002701.4 & 572 \\
\hline 3 & Vimentin & $\begin{array}{l}\text { F CGACCGCACACAGCAAGGCG } \\
\text { R- TCCCGGAGGCGCATGATGTC }\end{array}$ & NM003380.3 & 850 \\
\hline 4 & GAPDH & $\begin{array}{l}\text { F- GCCTTCCGTGTCCCCACTGC } \\
\text { R - GCTCTTGCTGGGGCTGGTGG }\end{array}$ & NM002046.3 & 330 \\
\hline 5 & Collagen type I & $\begin{array}{l}\text { F-CCCTCCCCAGCCACAAAGAGTCT } \\
\text { R-GGGTGACTCTGAGCCGTCGG }\end{array}$ & NM000088.31 & 348 \\
\hline 6 & Collagen type II & $\begin{array}{l}\text { F-CCGCGGTGAGCCATGATTCGC } \\
\text { R-GTCGTCGCAGAGGACAGTCCCAG }\end{array}$ & NM001844.4 & 210 \\
\hline 7 & Collagen type $\mathrm{X}$ & $\begin{array}{l}\text { F- CTCCTGGGGAACGAGGGCCA } \\
\text { R - GCTATGCCAGCTGGGCCAGG }\end{array}$ & NM000493.3 & 682 \\
\hline 8 & Aggrecan & $\begin{array}{l}\text { F- CGTGTAAAAAGGGCACAGCCACC } \\
\text { R- TTTGGAGGGGTGAGTGGGTGCA }\end{array}$ & NM001135.3 & 267 \\
\hline 9 & SOX9 & $\begin{array}{l}\text { F- AGCCGAAAGCGGAGCTCGAAACT } \\
\text { R- GCACTTAGGAAGGCGCGGGGT }\end{array}$ & NM000346.3 & 215 \\
\hline 10 & Smad 1 & $\begin{array}{l}\text { F- CCCTGTCTTTGTGCTGACTGGGT } \\
\text { R- CGCCCTGTTTCCACCCAAGAAGT }\end{array}$ & NM001003688.1 & 256 \\
\hline 11 & Smad 3 & $\begin{array}{l}\text { F- AGATCCTTTGCGGGTAGCCCTG } \\
\text { R- GGCCGGCTCGCAGTAGGTAA }\end{array}$ & NM001145104.1 & 191 \\
\hline 12 & MAPK 1 & $\begin{array}{l}\text { F- CGACCCGAGTGACGAGCCCAT } \\
\text { R- AAGACGGGCTGGAGACAGGACC }\end{array}$ & NM002745.4 & 229 \\
\hline
\end{tabular}




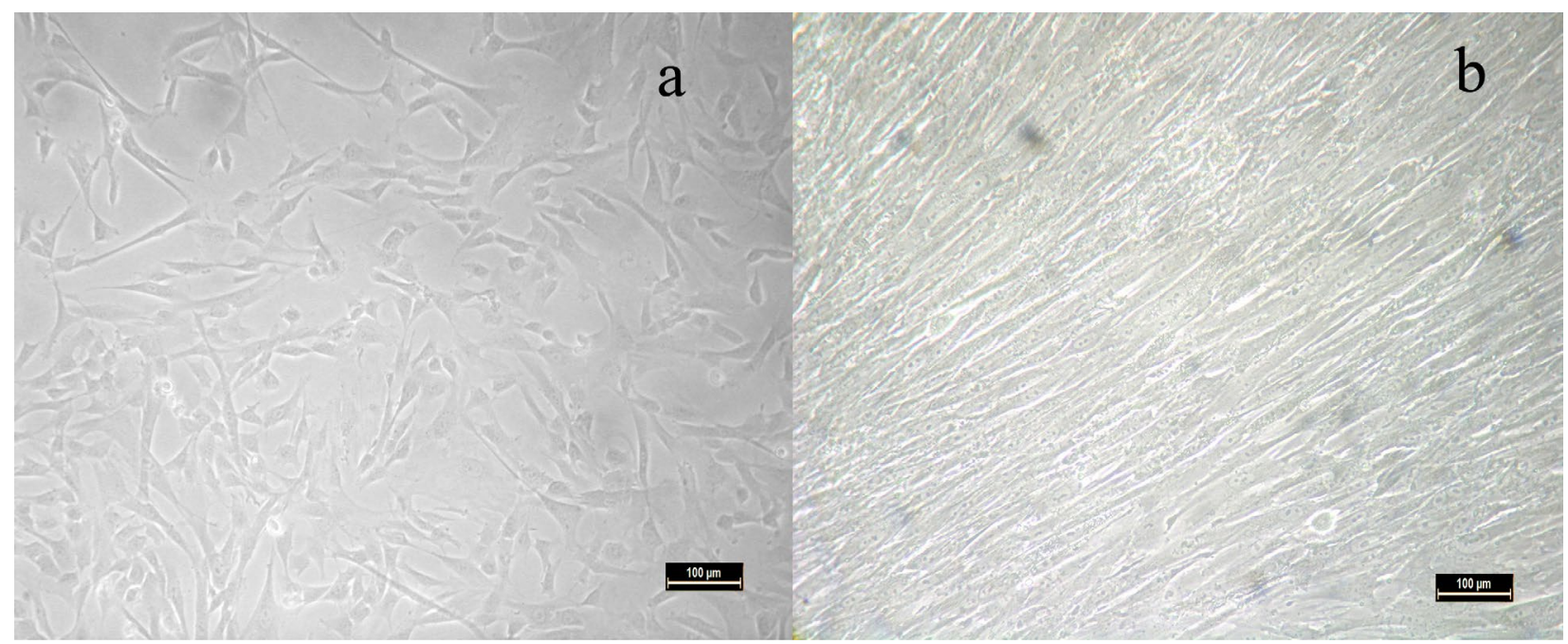

Fig. 1. hUCMSC at (a) $5^{\text {th }}$ day of culture and (b) confluence.
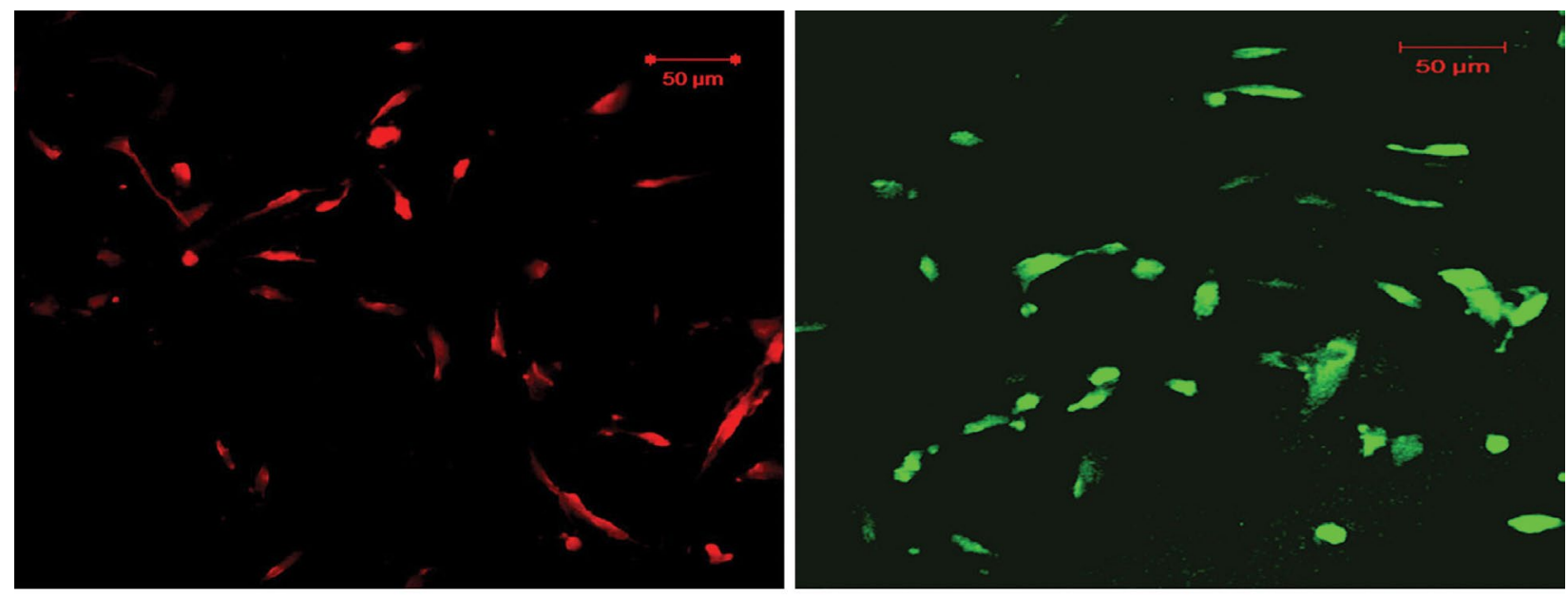

a

b
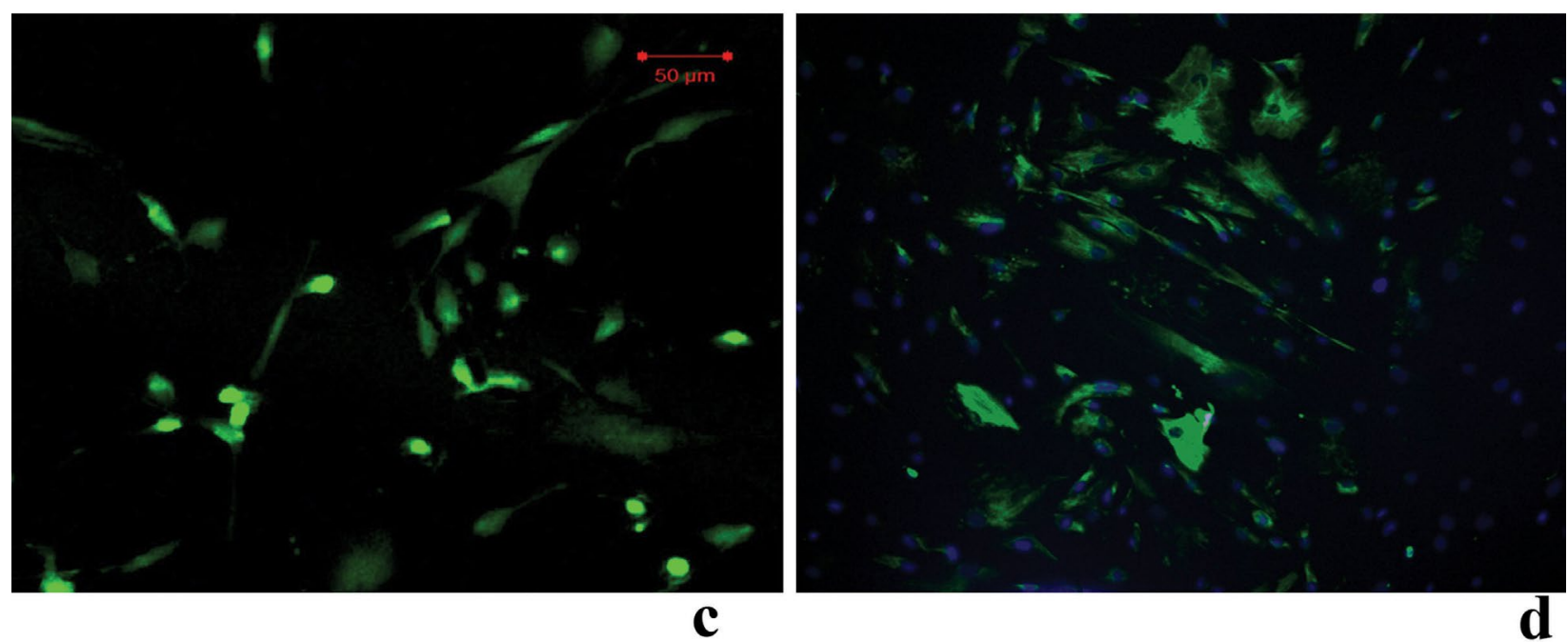

Fig. 2. Immunocytochemistry of hUCMSC showing specific markers (a) CD105, (b) CD44, (c) CD90, and (d) vimentin.

\section{Results}

\section{Isolation and expansion of hUCMSC in vitro}

Mesenchymal stem cells were successfully isolated from human umbilical cord, grown and propagated in culture. The digestion protocol yielded an average of approximately 10,000 cells per umbilical cord of $10 \mathrm{~cm}$ length in the initial isolate. In the present study, the cocktail of enzymes used, i.e. collagenase, dispase and hyaluronidase, helped in shortening the digestion time with better yield and reproducibility compared to the conventional protocol of $16 \mathrm{~h}$ digestion by collagenase type 2 described by Wang et al. (2004). The freshly isolated cells (P0) displayed a fibroblast-like appearance over the first 3-4 d of culture. 

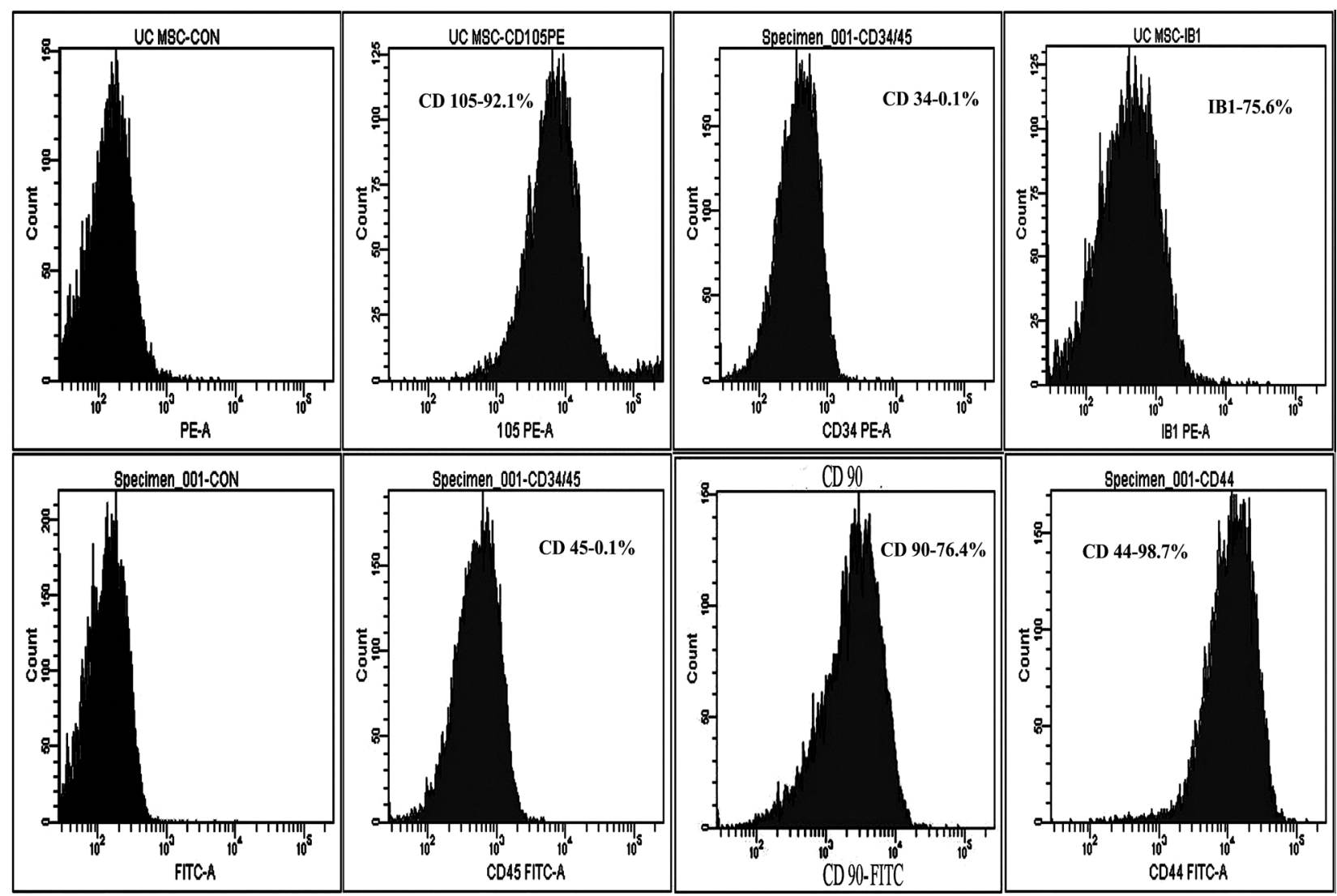

Fig. 3. Flow cytometric analysis of hUCMSC specific markers.

Once they gain $100 \%$ confluence in about 10-14 d, they typically appear as slender cells (Fig. 1). Medium was changed every alternate day and replenished with DMEM:HF12 (1:1) supplemented with $10 \%$ FBS. Cells were first passaged after $8 \mathrm{~d}$ (at $70 \%$ confluency) and then after every $4 \mathrm{~d}$. A homogenous cell layer was obtained by the first passage itself. Average population doubling time is in the range of $3.2 \mathrm{~d}$ for $\mathrm{P} 2$ cells and was not significantly altered by passage number. After 4 weeks of successive passage, the cells were harvested at an average density of 2.6-3.1 x $10^{7}$ cells at passage $4(n=6)$.

\section{Phenotypic characterisation of hUCMSC}

Immunocytochemistry revealed that the cells expressed vimentin, an intermediate filament characteristic of cells of mesodermal origin, CD105 (endoglin), a member of TGF beta receptor super family, CD44, a hyaluronate receptor, and CD90 (Fig. 2). Flow cytometric analysis showed that the population is homogenous strongly positive for CD44 (98.7\%), CD90 (76.4\%), CD105 (92.1\%) and CD29 (75.6\%) and negative for CD45 (0.1\%) and CD34 (0.1\%), which are haematopoietic lineage markers (Fig. 3). The cells (hUCMSCs) expressed some of the transcription factors that are mainly expressed in embryonic stem cells, such as Oct-4 and Nanog, at the mRNA levels, as demonstrated by PCR analysis (Fig. 4).

The multi differentiation potential of isolated mesenchymal stem cells from cord matrix was assessed $21 \mathrm{~d}$ after adipogenic and osteogenic induction. Osteogenic

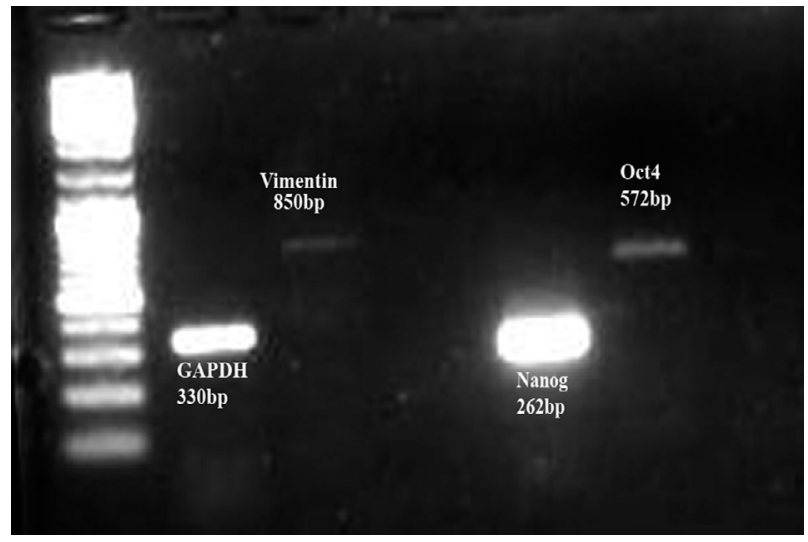

Fig. 4. Gel picture showing bands of pluripotency markers Oct 4 and Nanog.

differentiation is demonstrated by calcium phosphate mineralisation, which is stained positive by Alizarin Red stain (Fig. 5a) Appearance of numerous large round intra cytoplasmic granules stained by Oil Red stain suggests that cells have differentiated towards an adipogenic lineage (Fig. 5b).

\section{Chondrogenic differentiation of hUCMSC in PVA- PCL scaffolds}

hUCMSCs were subjected to chondrogenesis by culturing in 3D PVA-PCL scaffolds. The schematic representation 


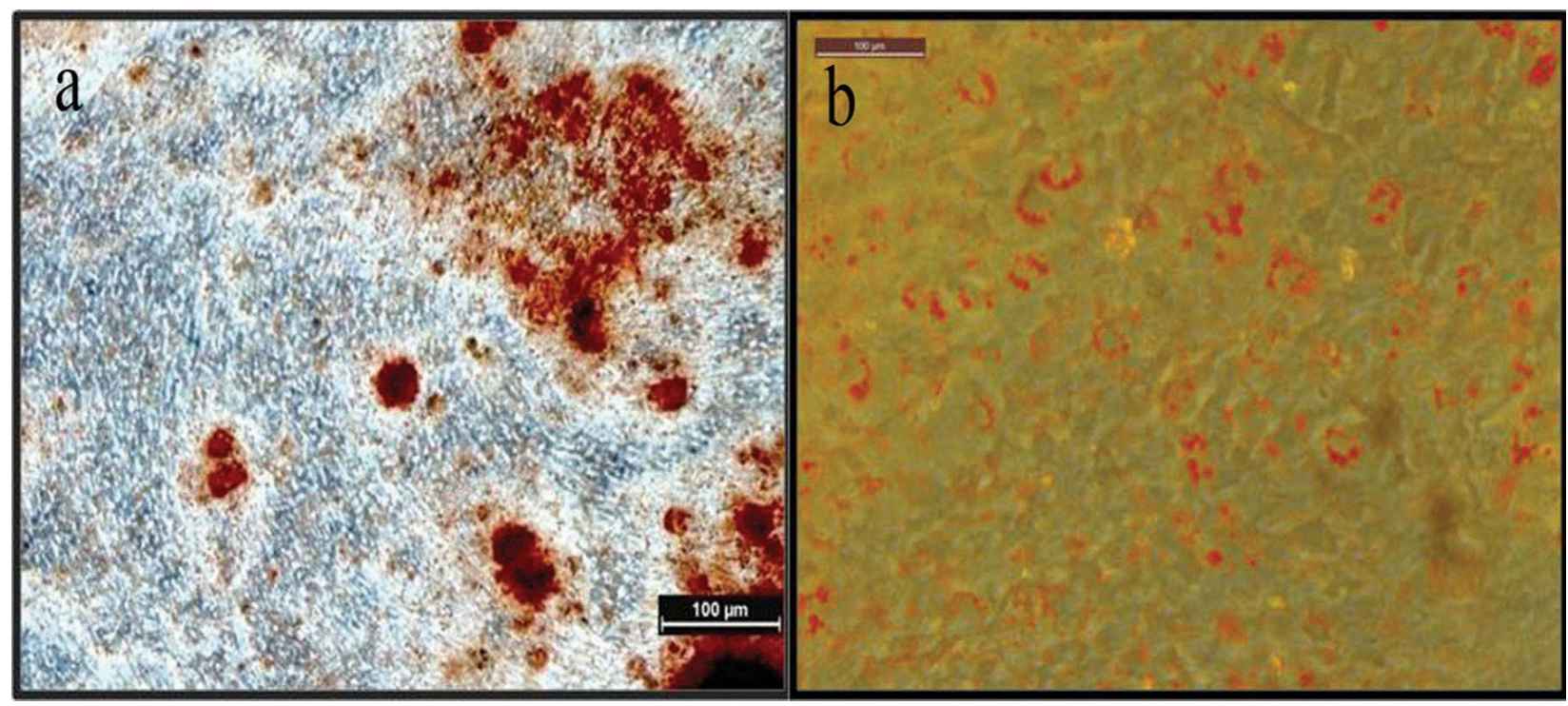

Fig. 5. Multidifferentiation potential of hUCMSC. (a) Osteogenic differentiation, and (b) adipogenic differentiation.

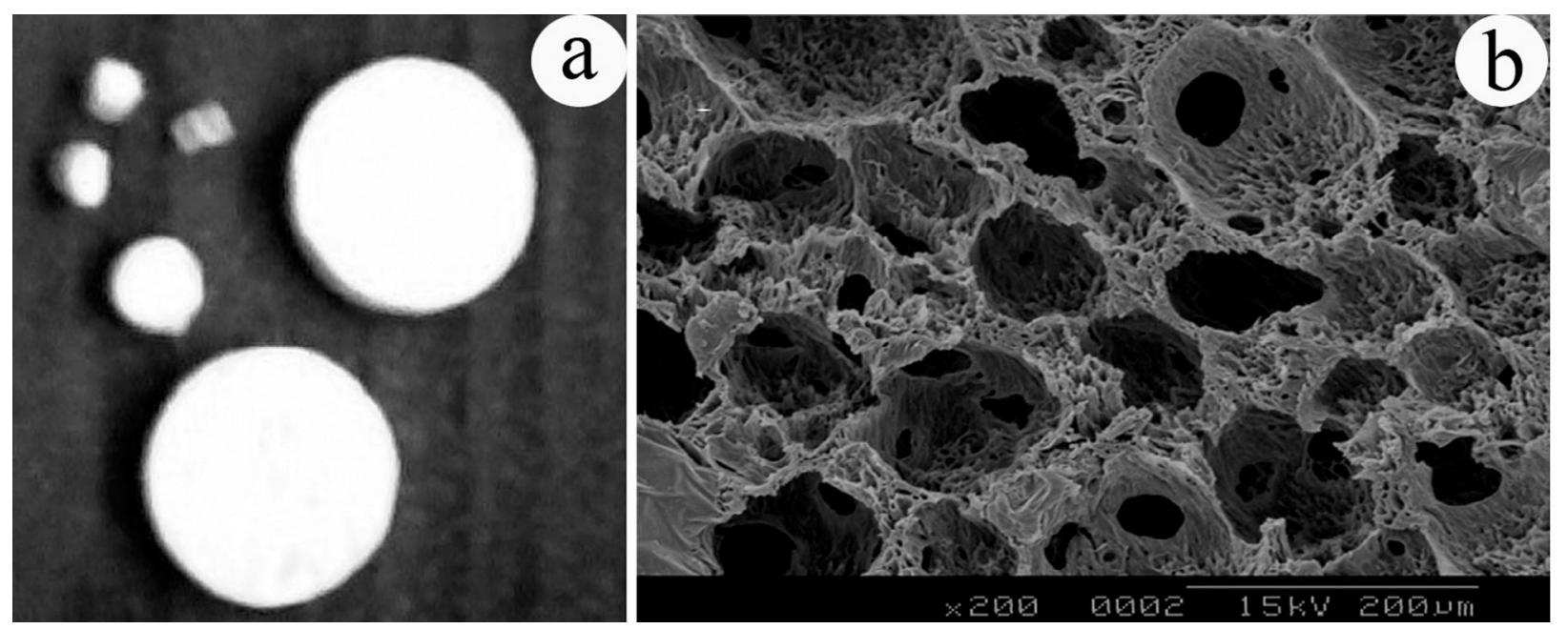

Fig. 6. (a) PVA-PCL scaffolds, and (b) SEM picture of PVA-PCL scaffolds showing open interconnected pores.

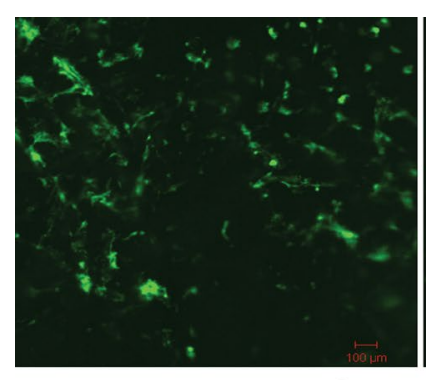

$\mathbf{a}$

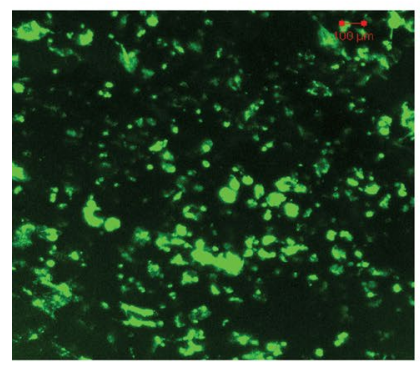

b

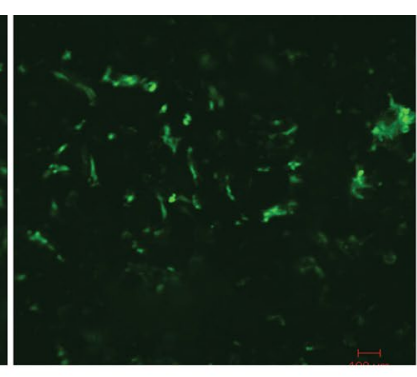

c

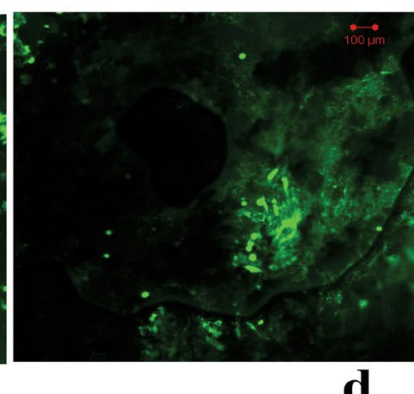

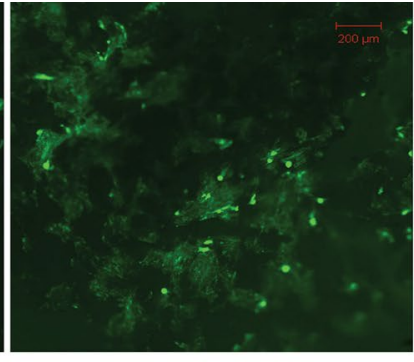

$\mathbf{e}$

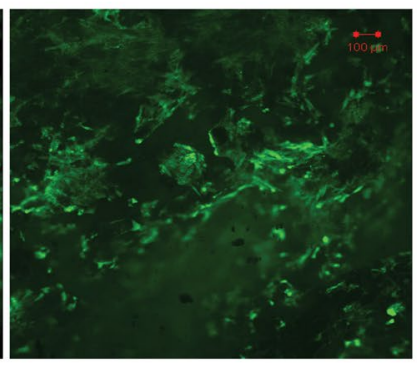

f

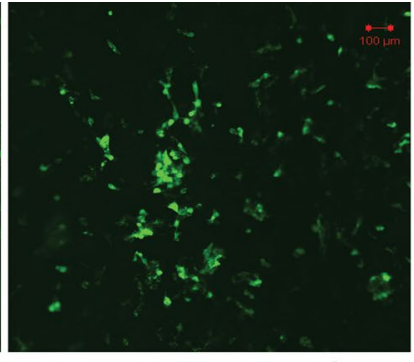

$\mathbf{g}$

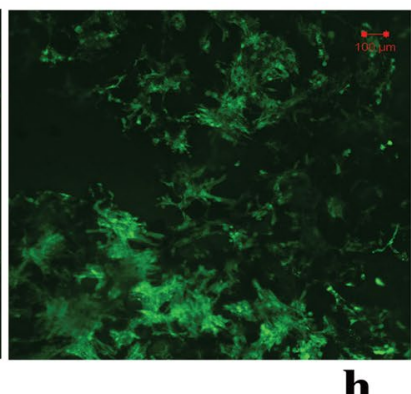

Fig. 7. Live/dead image of cell-seeded constructs showing the viability and distribution of cells. (a) Control, (b) BMP2, (c) TGF $\beta 1$, (d) TGF $\beta 1+B M P 2$, (e) TGF 33 , (f) TGF $\beta 3+B M P 2$, (g) IGF, and (h) IGF+BMP2. 


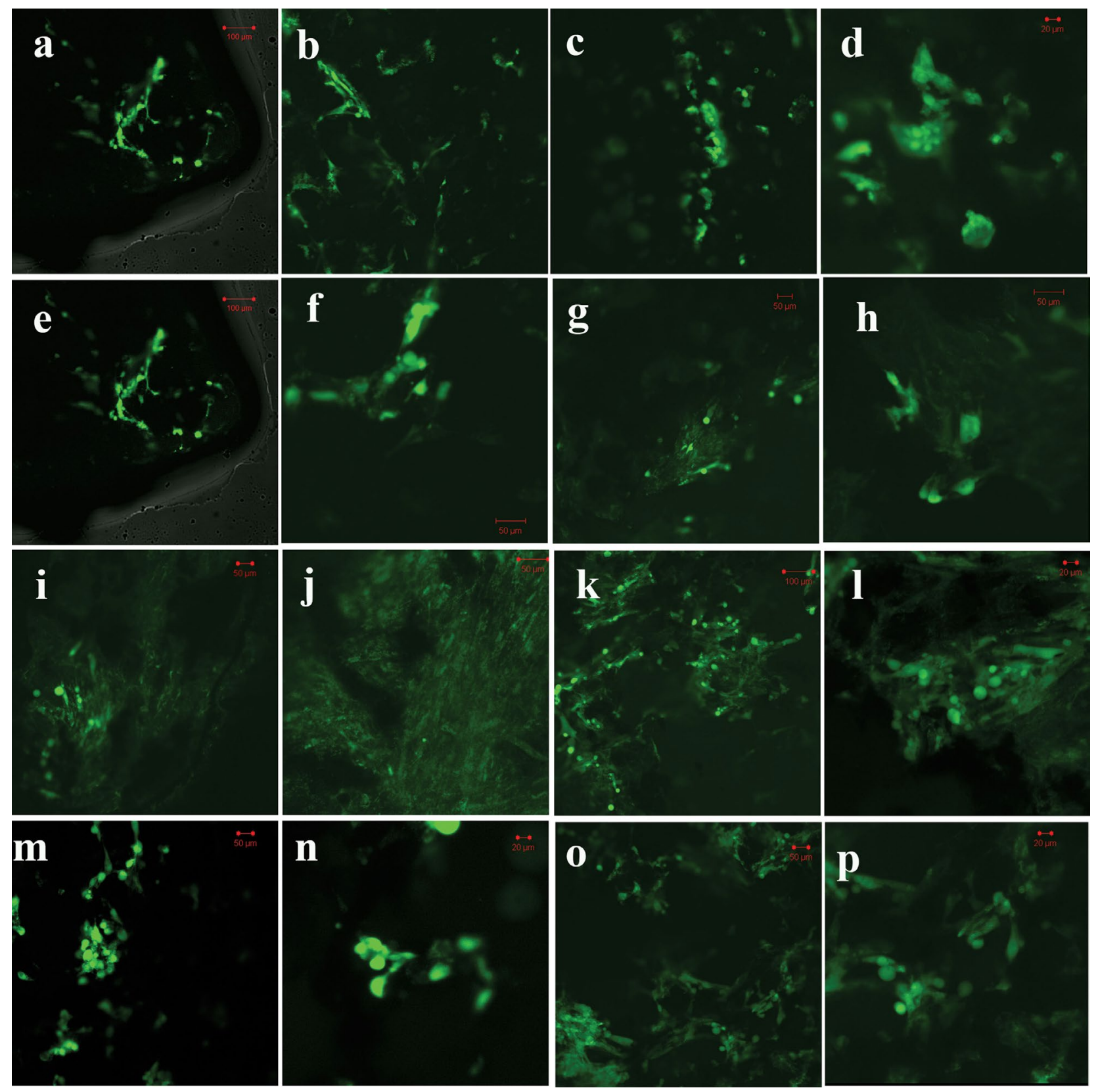

Fig. 8. Live/dead image of cell-seeded constructs showing the morphology of cells. (a) Control, (c) BMP2, (e) TGF $\beta 1$, (g) TGF $\beta 1+B M P 2$, (i) TGF 33 , (k) TGF $33+B M P 2$, (m) IGF, (o) IGF+BMP2 at 10x magnification, and (b) control, (d) BMP2, (f) TGF $\beta 1$, (h) TGF $\beta 1+B M P 2$, (j) TGF $\beta 3$, (l) TGF $33+$ BMP2, (n) IGF, (p) IGF+BMP2 at higher magnification $(20 \mathrm{x})$.

of the PVA-PCL semi-IPN is shown in Fig. 6. The scaffold was highly porous with open interconnected porous structure and had high medium uptake ability. The seeding methodology of cells in PVA-PCL scaffolds, standardised in the laboratory (based on earlier experiments), gives sufficient time for cell attachment and hence was not evaluated in the present study. For growth factor treatment to assess chondrogenic differentiation, there were 8 different groups. Chondrogenic medium was supplemented with human transforming growth factor $\beta 1$ (TGF $\beta 1$, $10 \mathrm{ng} / \mathrm{mL}$ ) transforming growth factor $\beta 3$ (TGF $\beta 3,10 \mathrm{ng} /$ $\mathrm{mL}$ ), insulin-like growth factor (IGF, $10 \mathrm{ng} / \mathrm{mL}$ ), bone morphogenic protein (BMP2, $25 \mathrm{ng} / \mathrm{mL}), \mathrm{TGF} \beta 1+\mathrm{BMP} 2$ (10 ng/mL, $25 \mathrm{ng} / \mathrm{mL})$, TGFß3+BMP2 (10 ng/mL, $25 \mathrm{ng} /$
$\mathrm{mL}), \mathrm{IGF}+\mathrm{BMP} 2(10 \mathrm{ng} / \mathrm{mL}, 25 \mathrm{ng} / \mathrm{mL})$ accordingly. Control culture medium was without any growth factor incorporation.

Evaluation of degree of hUCMSC chondrogenesis Analysis of cell seeded constructs

Cell viability, morphology and distribution

The confocal images of live-dead assay performed on the cell-seeded construct after culture provide information on the viability, morphology and overall distribution of the cells in PVA-PCL scaffolds (Fig. 7). hUCMSC remained viable in the scaffolds under all growth factor supplemented conditions, as shown by green cells after live-dead assay. The cells were able to grow inside the scaffold due to its 


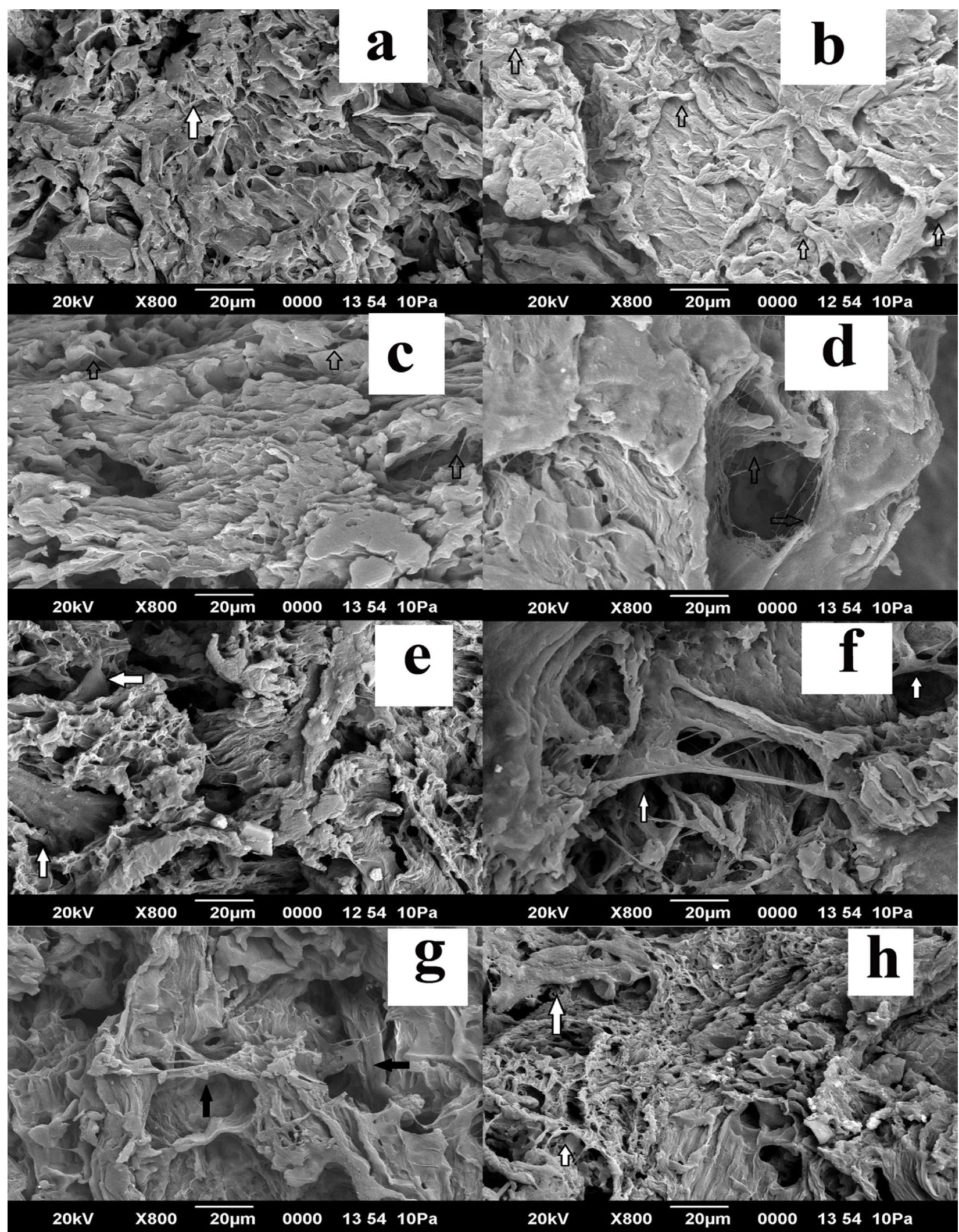

Fig. 9. SEM images of cell-seeded constructs after culture. (a) Control, (b) BMP2, (c) TGF $\beta 1$, (d) TGF $\beta 1+B M P 2$, (e) TGF 33 , (f) TGF $\beta 3+B M P 2$, (g) IGF, (h) IGF+BMP2. The arrows in the figure denote cells on the surface of the scaffold.

highly porous nature, which facilitated the free diffusion of nutrients deep within the scaffold. Interestingly, it was observed that the cells under BMP2 supplementation alone assumed a typical round morphology which was different from all other groups. In higher magnification (20x), it was observed that an elongated morphology still persists in TGF $\beta 1$ supplemented group. Round cells resembling chondroblasts were seen in TGF $\beta 3$ and IGF supplemented groups, and in BMP2 supplemented groups alone typical large round cells were seen (Fig. 8). SEM 
GAG ESTIMATION

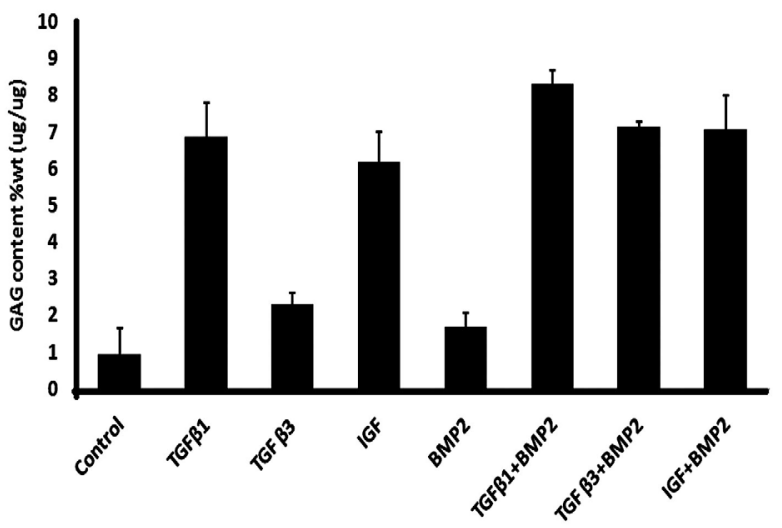

Fig. 10. Estimation of total GAGs by DMMB assay. All values are expressed as mean \pm standard deviation from three different replicates. * Statistical significance of $p<0.05, * * p<0.01$.
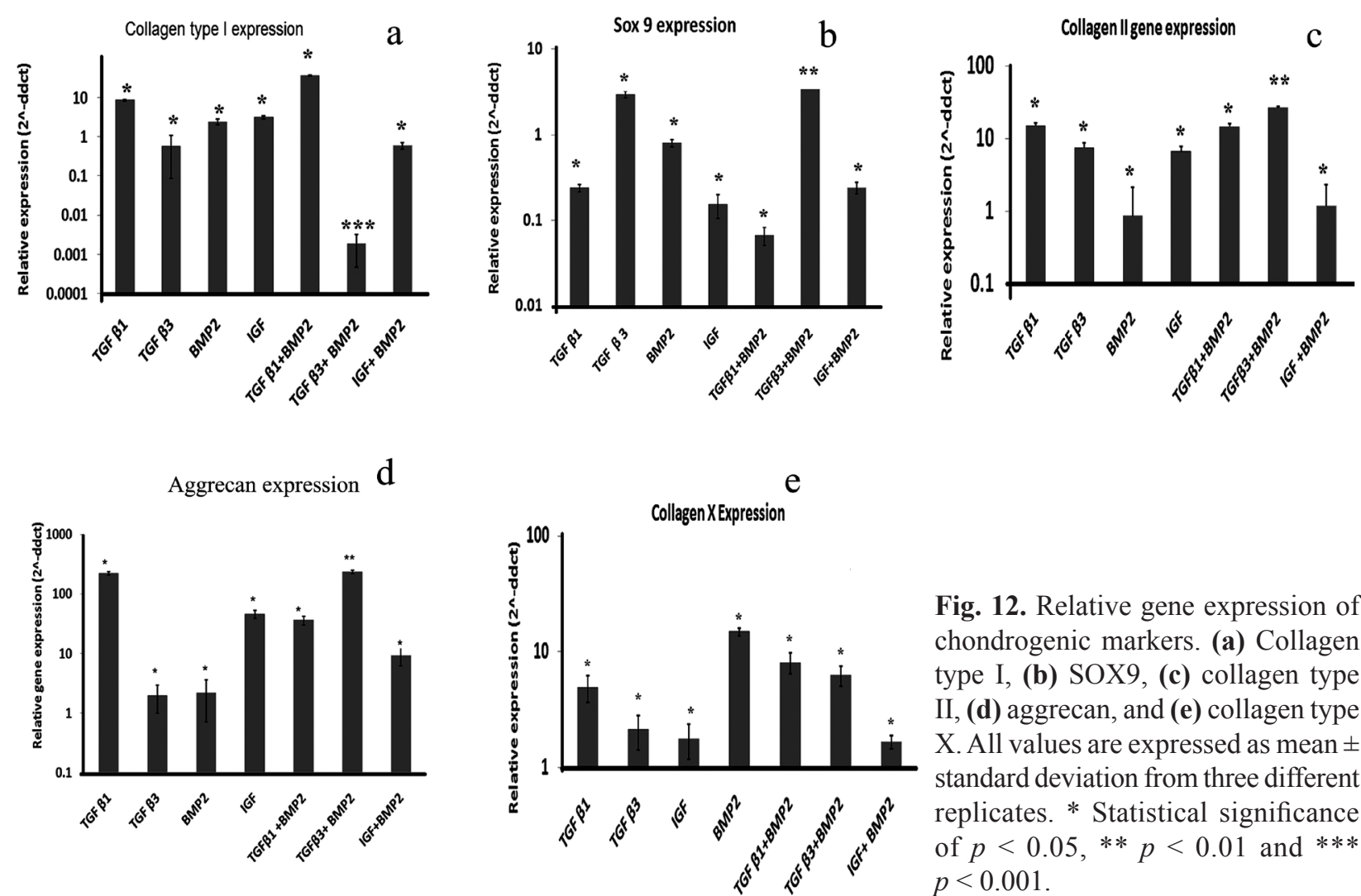

Fig. 12. Relative gene expression of chondrogenic markers. (a) Collagen type I, (b) SOX9, (c) collagen type II, (d) aggrecan, and (e) collagen type $\mathrm{X}$. All values are expressed as mean \pm standard deviation from three different replicates. * Statistical significance of $p<0.05, * * p<0.01$ and $* * *$ $p<0.001$. images at different magnification also reflect on the cell morphology and distribution of extracellular matrix. The cells appeared in patches and had elongated morphology. In the combination group, a sheet of extracellular matrix covering the surface of the scaffolds was seen. However, in the BMP2 alone supplemented group round cells were seen (Fig. 9).

\section{Total glycosaminoglycan content by DMMB assay}

DMMB assay of the constructs after the culture period showed that the mean \pm SD levels of s-GAGs were increased in all the growth factor-treated groups (except BMP2 alone supplemented group) over the control $(p<0.05)$. Interestingly, the total GAG content is seen increased in combination groups rather than individual supplemented groups $(p<0.01)$, with TGF $\beta 1+$ BMP2 showing the highest value $(8.2 \mathrm{wt} \%)$ followed by TGF $33+$ BMP2 group (7.2 wt \%). Among the individual groups, TGF $\beta 1$ (6.8 wt \%) showed higher GAG content than others. However, there was only a very minimal increase $(1.68 \mathrm{wt} \%)$ in s-GAG content in construct supplemented with BMP2 (Fig. 10).

\section{Total DNA content by picogreen assay}

The proliferation of hUCMSCs in different growth factor conditions was evaluated by genomic content of the constructs (Fig. 11). The proliferation rate of cells in growth factor supplemented constructs was comparable to 


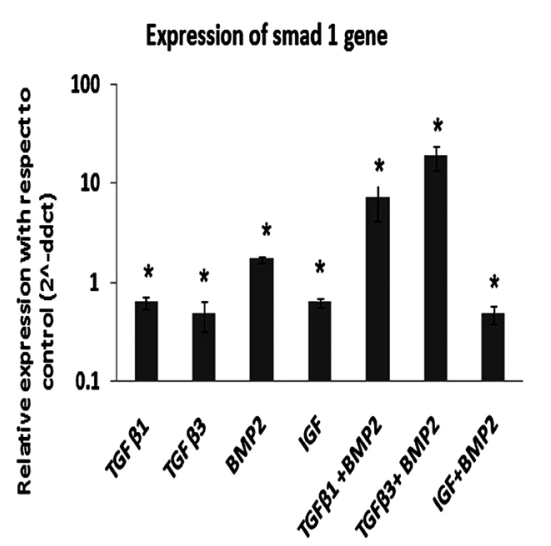

a

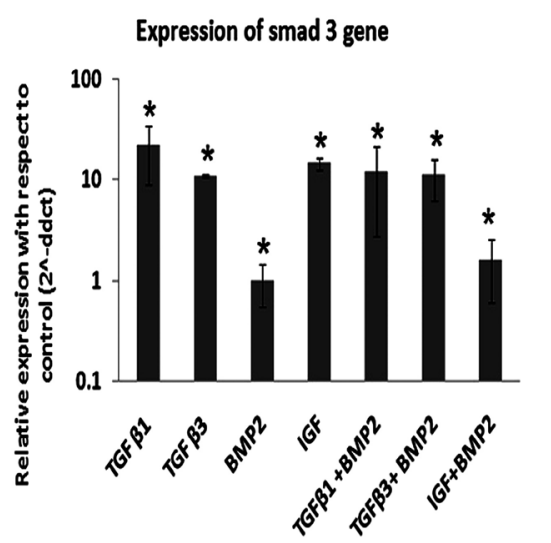

b

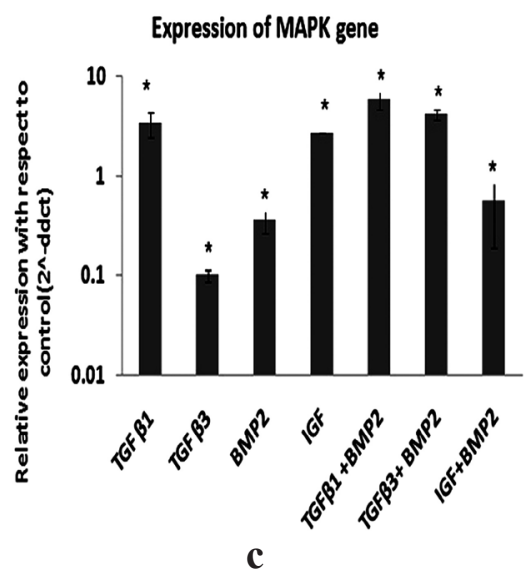

Fig. 13. Relative gene expression of signaling pathway genes. (a) Smad 1, (b) Smad 3, and (c) MAPK genes. All values are expressed as mean \pm standard deviation from three different replicates. $*$ Statistical significance of $p<0.05$.

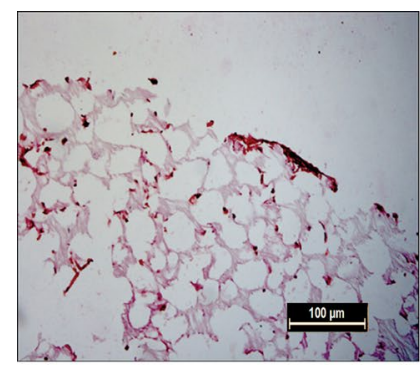

$\mathbf{a}$

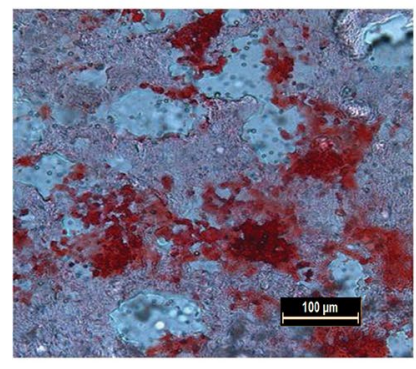

e

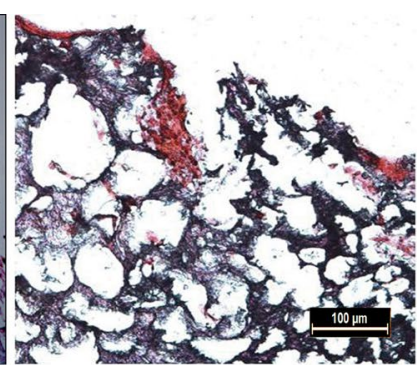

b

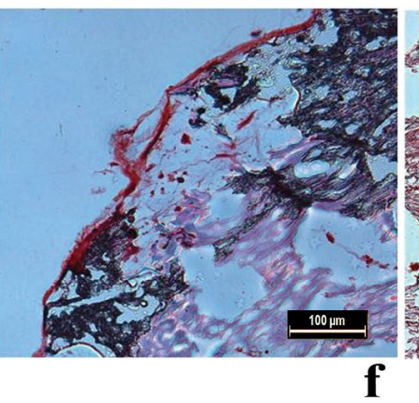

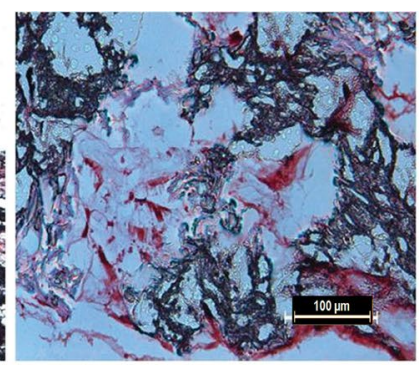

c

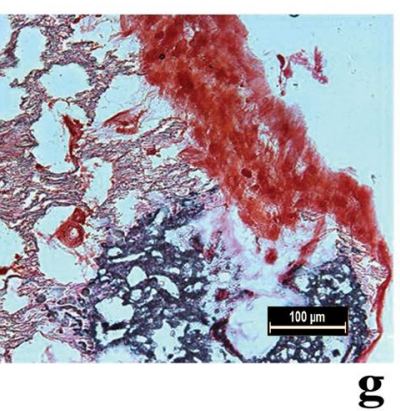

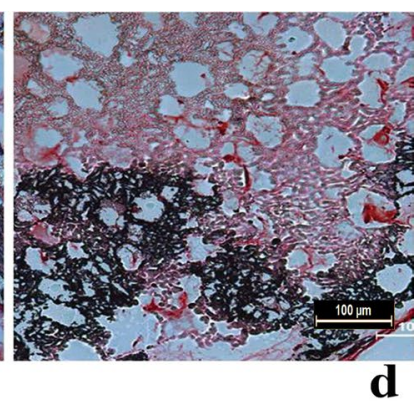

d

Fig. 14. Safranin O staining for glycosaminoglycans (n=3). (a) Control, (b) TGF 1 , (c) TGF 33 , (d) IGF, (e) BMP2, (f) TGF $\beta 1+B M P 2$, (g) TGF $33+\mathrm{BMP} 2$, and (h) IGF+BMP2.

that of control construct. However, the DNA content was higher in BMP2 and IGF supplemented group (4.2 and $3.9 \mu \mathrm{g} / \mathrm{mL}$, respectively).

\section{Gene expression of chondrogenic markers}

The mRNA expression level of various marker genes relevant to chondrogenic differentiation of hUCMSCs was evaluated by RT PCR analysis. The relative expression of collagen type I gene with respect to control is shown in Fig. 12a. There was a high level of up-regulation of collagen type I gene in TGF $\beta 1$ (fold increase of 8.61) and TGF $\beta 1+$ BMP2 supplemented group (36 fold). IGF and BMP2 also up-regulated collagen type I gene expression (3.12 fold). Interestingly, the expression level was lesser in the TGF $\beta 3$-supplemented group ( 0.05 fold $)$ with very minimal expression (0.0018 fold) observed in TGF $\beta 3+\mathrm{BMP} 2$ combination group $(p<0.001)$. The results on SOX9 expression with respect to control is shown in (Fig. 12b). The combination group showed a relative increase in SOX9 expression when compared to individual growth factors. The TGF $\beta 3+\mathrm{BMP} 2$ group showed maximum expression of SOX9. The expression of collagen type II was up-regulated in all growth factor supplemented constructs. Addition of BMP2 was found to have little effect on collagen type II gene expression in case of TGF $\beta 1$ and IGF growth factor supplemented constructs. However, a significant increase in expression is noted in the case of the TGF $\beta 3$ and BMP 2 combination (fold increase of 13.36, $p<0.01$ ). Aggrecan expression was also up-regulated in all growth factor constructs, with TGF $\beta 3$ and BMP 2 showing the maximum expression (200 fold) (Figs 12c, 12d). Collagen type X expression is seen up-regulated in all growth factor supplemented constructs and addition of BMP2 has increased the expression of collagen type X (Fig. 12e). 


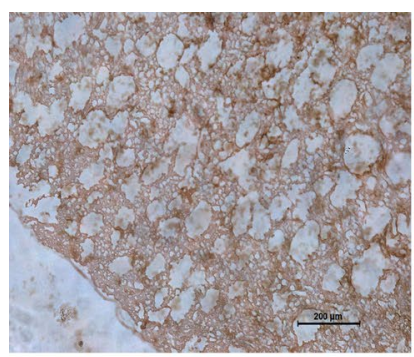

$\mathbf{a}$

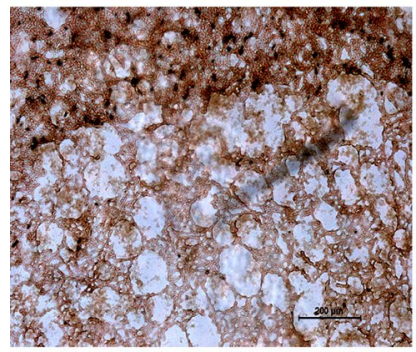

$\mathbf{e}$

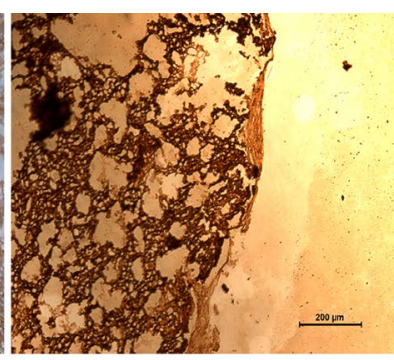

b

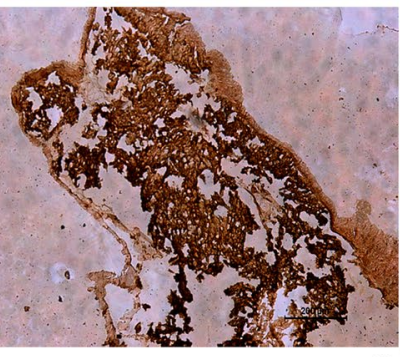

$\mathbf{f}$

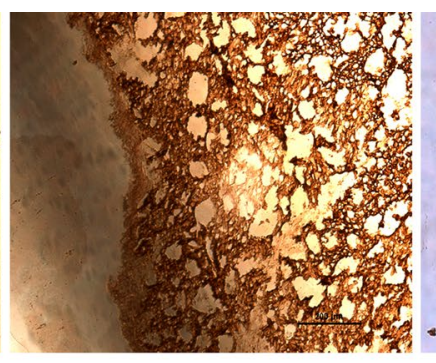

c

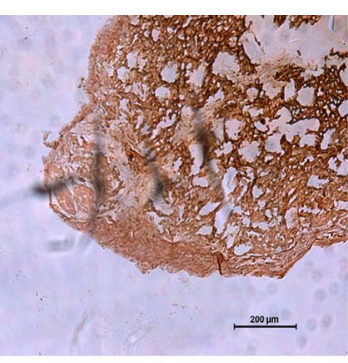

d

Fig. 15. Immunostaining for collagen type II $(n=3)$. (a) Control, (b) TGF $\beta 1$, (c) TGF $\beta 3$, (d) IGF, (e) BMP2, (f) TGF $\beta 1+B M P 2$, (g) TGF $\beta 3+B M P 2$, and (h) IGF+BMP2. Negative control groups (not shown) confirmed the absence of non-specific staining.

Signalling pathway analysis

Smad 1, the substrate for BMP2 signalling molecules, was expressed in all the constructs. However, an up-regulated expression when compared to control, i.e. without growth factors, was observed in constructs supplemented with BMP2, except in IGF+BMP2 supplemented constructs $(p<0.001)$ (Fig. 13a). Up-regulated expression of Smad 3, which is the substrate for activated TGF beta receptors, was observed in all the growth factor supplemented constructs except the one supplemented with BMP2 alone, which was similar to that of control cells (Fig. 13b). Fig. 13c shows the gene expression of mitogen activated protein kinase (MAPK) in the constructs. MAPK is expressed in all the constructs including the cells not treated with growth factor. However, when compared to control, significant up-regulation was seen in TGF $\beta 1$-supplemented constructs (3.3 and 5.8 fold, respectively).

\section{Histology and immunohistochemical analysis}

The histological analysis of the constructs revealed the distribution of cells inside the scaffold and the deposition of extracellular matrix. Safranin O stains the glycosaminoglycans orange-red that can be visualised (Fig. 14). The GAG deposition was higher in TGF $\beta 3$ and BMP2 constructs, as indicated by their high intensity of staining. Fig. 15 shows the images for immunostaining of collagen type II in PVA-PCL cell constructs. On pericellular localisation of specific extracellular matrix molecules, collagen type II could be visualised in cellseeded construct sections confirming that hUCMSC chondrogenic differentiation has occurred.

\section{Discussion}

Mesenchymal stem cells were successfully isolated from human umbilical cord, grown and propagated in culture. The minimal criteria for the definition of MSCs, as set by International Society for Cellular Therapy, are the ability of MSCs to adhere to plastics under standard conditions and their phenotypical characterisation based on the expression of a set of surface antigens and in vitro differentiation potential (Dominici et al., 2006). A randomly selected isolate of passage one was fully characterised by plastic adherence, for cell specific markers by immunocytochemistry, flow cytometry and PCR analysis, and for its multi lineage differentiation potential into osteogenic and adipogenic lineages. These cells, like bone marrow mesenchymal cells, are plastic adherent, express markers of mesenchymal cells, such as CD10, CD13, CD29, CD44, CD90 and CD105, and lack markers of haematopoietic origin. The fact that cells expressed the pluripotency markers Oct- 4 and Nanog, as evidenced by PCR analysis, that are essential for maintaining pluripotency and proliferative capacity in embryonic stem cells (Medvedev et al., 2008), reflects their primitive characteristics and are responsible for their high expansion potential. Compared with other adult sources, which possess age dependent differentiation and expansion potential, hUCMSCs have high expansion and proliferation ability and multi-differentiation potential that makes it an attractive stem cell source for tissue engineering and other cell based therapies.

It has been well established that during embryogenesis, the development of cartilage is initiated by condensation of 
mesenchymal progenitors, and the cell-cell contact arising from condensation appears to be crucial for the onset of chondrogenesis. For simulating this condensation, a three dimensional environment is proposed that provides better cell-cell as well as cell-matrix interactions. PVA-PCL semi-IPN porous structure is selected because earlier results from our laboratory have shown that $3 \mathrm{D}$ semi-IPN scaffold exhibited synergistic properties of both polyvinyl alcohol, with a hydrophilic domain, and polycaprolactone, which has a hydrophobic domain. The scaffold is highly porous with an open interconnected porous structure and has a high/medium uptake ability to promote efficient transfer of nutrients to all the cells. It is cell compatible, biodegradable and has adequate mechanical stability to withstand the load imparted by the cells during in vitro culture. The scaffold is also found to promote the secretion of cartilage specific molecules, as detailed in a previous study from our laboratory (Mohan and Nair, 2010).

Furthermore, in native cartilage, the process of chondrogenesis involving recruitment of mesenchymal cells, their condensation and differentiation with the elaboration of specific extracellular matrix is regulated by an array of chemical morphogens called growth factors which may act either synergistically or distinctively. Although there are studies showing the successful chondrogenic differentiation of umbilical cord MSCs in a few 3D scaffolds with various growth factors (Zhao and Detamore, 2010; Fong et al., 2010), a comparative analysis of the effect of different growth factors on hUCMSC in $3 \mathrm{D}$ scaffolds is lacking. Therefore, it is necessary to identify an appropriate combination of growth factors which promotes hUCMSC chondrogenesis. So, after characterising hUCMSC for their ability to proliferate, selfrenew and express typical mesenchymal stem cell surface markers, the potential of hUCMSC to differentiate towards the chondrogenic lineage by different growth factors and the optimal culture conditions to drive this differentiation were evaluated.

hUCMSCs were subjected to chondrogenesis by culturing in 3D PVA-PCL scaffolds and submitting to chondrogenic induction with a basal medium (without FBS) containing conventionally, dexamethasone, ascorbate, insulin, transferrin and selenium (Derfoul et $a l ., 2006)$. It has been well established that members of transforming growth factor beta family (TGF $\beta 1,2$ and 3 ) are full inducers of chondrogenesis, leading to the elaboration of chondrocyte specific markers, collagen type II and aggrecan, even when added as single factors (Blunk et al., 2002; Diekman et al., 2009). On the other hand, IGF - an anabolic growth factor, has also been described to direct bone marrow MSC chondrogenesis (Longobardi et al., 2006). However, it has been widely observed that IGF has little or no effect on chondrogenic differentiation in the presence of insulin-transferrin-selenium (ITS) with MSCs. This is because of the competitive inhibition of insulin and IGF. Hence, in the present study, instead of ITS in chondrogenic medium supplemented with IGF, only transferrin and selenium were used. Combined with the knowledge that BMP signalling is required for the formation of precartilagenous condensation and differentiation of chondroprecursors and, in adult articular cartilage homeostasis, by enhancing proteoglycan and type II collagen synthesis (Zhang et al., 2002; Schmitt et al., 2003; Noel et al., 2004), the extent of hUCMSC chondrogenesis by these growth factors, when administered singly or in combination with BMP2, is evaluated after $28 \mathrm{~d}$ culture with the respective growth factors.

A constant seeding density of $5 \times 10^{5}$ cells per scaffold was kept for all the constructs, for getting comparative data on the chondrogenic efficiencies of different chondrogenic growth factors in in vitro chondrogenesis of hUCMSC. However, comparisons with other seeding densities, as well as other seeding methodology, were not attempted in this particular study. The viability and growth of cells inside the scaffold is attributed to the highly porous nature of the scaffold. This facilitated the free diffusion of nutrients deep within the scaffold and substantiated the common finding that three-dimensional culture of cells in scaffolds is superior to 2D culture and pellet culture. After growth-factor treatment changes in morphology could be evident. With the knowledge, from existing literature, it could be inferred that the presence of TGF $\beta 1$ might have directed the stem cells to differentiate to a smooth muscle phenotype (Gong and Niklason, 2008) and the addition of BMP2 growth factor alone might have contributed to the differentiation of an osteogenic phenotype (Van der Zande et al., 2008).

The typical extracellular matrix of hyaline cartilage consists of a fibrillar collagen network with entrapped glycosaminoglycan molecules. Hence, sulphatedGAGs have been considered as one of the markers for chondrogenic differentiation. DMMB is a cationic dye which readily binds to the negatively charged s-GAGs and proteoglycans, resulting in the metachromatic conversion of the dye that is measured at $525 \mathrm{~nm}$. DMMB assay of the constructs after the culture period showed that the mean \pm SD levels of s-GAGs were increased in all the growth factor-treated groups (except the BMP2 alone supplemented group) over the control, suggesting that chondrogenic differentiation has taken place under growth factor supplementation. However, there was only a very minimal increase in s-GAG content in constructs supplemented with BMP2, suggesting that the cells might have differentiated to an osteogenic lineage rather than a chondrogenic one, confirming the established fact that BMP2 has an osteoconductive effect in hUCMSC differentiation (Ciavarella et al., 2009; Hou et al., 2009). Total GAG produced is a feature of the differentiation state of the cells. Retention of GAGs within the scaffolds is a property of the scaffold itself and the maturity of the pericellular matrix. In a newly developed construct, the bulk of the newly synthesised GAG is released into the culture medium, as the pericellular matrix is not sufficiently developed to retain the newly produced GAG. In this study the GAG secreted into the medium was very minimal. This also reflects on the ability of the scaffold to retain the synthesised GAG molecules within the construct. Therefore, the results of chondrogenic differentiation, as extrapolated from s-GAG content in different growth factor supplemented constructs, were of the following order: BMP2 $<$ TGF $\beta 3<$ IGF $<$ TGF $\beta 1<$ IGF+BMP2 $<$ TGF $\beta 3+\mathrm{BMP} 2<\mathrm{TGF} \beta 1+\mathrm{BMP} 2$. 
Zhao and Detamore (2010) have studied the chondrogenic differentiation of stem cells in human umbilical cord stroma, with PGA and PLLA scaffolds in the presence of TGF $\beta 1(10 \mathrm{ng} / \mathrm{mL})$ as growth factor, and reported a highest GAG content of $11.1 \pm 2.4 \mu \mathrm{g} /$ scaffold and $10.9 \pm 2.3 \mu \mathrm{g} / \mathrm{scaffold}$ for PGA and PLLA scaffolds on the initial day of seeding, which were decreased with culture time. However, a study by Wang and Detamore (2009) reported an increase in GAG content of tissue engineered constructs with hUCMSC of about $37 \pm 3 \mu \mathrm{g} /$ scaffold, $40 \pm 5 \mu \mathrm{g} / \mathrm{scaffold}$ and $36 \pm 3 \mu \mathrm{g} / \mathrm{scaffold}$ for IGF (10 ng/mL), IGF (100 ng/mL) and TGFß3 (20 ng/ $\mathrm{mL})$ at 6 weeks of culture with an initial seeding density of 50 million cells/scaffold and pretreatment with IGF-1. A comparative study on human bone marrow stem cells (hBMSC) and hUCMSC chondrogenesis, by the same group, reported a GAG content of $16 \pm 2 \mu \mathrm{g} / \mathrm{scaffold}$ for hUCMSC and $12 \pm 1 \mu \mathrm{g} /$ scaffold for hBMSC at 6 weeks with TGF $\beta 1(10 \mathrm{ng} / \mathrm{mL})$ as chondrogenic growth factor (Wang et al., 2009). Even though these results cannot be directly compared with the results of our studies, due to the differences in culture conditions, duration of culture, initial seeding condition etc., it could be concluded that PVA-PCL scaffolds support the growth and chondrogenic differentiation of hUCMSC.

The proliferation rate of cells in growth factor supplemented constructs was comparable to that of control constructs. However, the DNA content was higher in BMP2 and IGF supplemented groups (4.2 and $3.9 \mu \mathrm{g} / \mathrm{scaffold})$, respectively, in accordance with the previous reports on the anabolic effect of BMP2 and IGF on cells (Bonassar et al., 2001; Majumdar et al., 2001).

Collagen type I is the primary collagen present in skin, bone and fibrocartilage as well as umbilical cord but not in hyaline cartilage (Mayne, 1989; Karahuseyinoglu et al., 2007). It is also seen expressed in the initial stages of mesenchymal condensation. Hence, its presence may suggest the non-chondrogenic commitment of the cells or undifferentiated state. In the present study, expression of the collagen type I gene was observed in all of the studied culture systems. The up-regulated expression in TGF $\beta 1$ and TGF $\beta 1+B M P 2$ supplements was consistent with the previous observation that TGF $\beta 1$ induces smooth muscle differentiation and fibrocartilaginous differentiation $(\mathrm{Hu}$ et al., 2003; Moreau et al., 2005). The results in relative expression of collagen I suggesting the non-chondrogenic lineage commitment of hUCMSC in different growth factor-supplemented media is of the order: TGF $\beta 3+\mathrm{BMP} 2$ $<\mathrm{TGF} \beta 3<\mathrm{IGF}+\mathrm{BMP} 2<\mathrm{BMP} 2<\mathrm{IGF}<\mathrm{TGF} \beta 1<$ TGF $\beta 1+$ BMP2

Up-regulated expression of collagen type II in growth factor-supplemented constructs suggests that stem cell differentiation to chondrocytes requires the presence of chondrogenic growth factors. Addition of BMP2 was found to have little effect on collagen type II gene expression in the case of TGF $\beta 1$ and IGF growth factorsupplemented constructs. On the other hand, significant increase in expression in the case of TGF 33 and BMP2 combination may be due to the synergistic action of both the growth factor receptors. The nuclear transcription factor SOX9 is required for establishing the pre-cartilaginous condensations and initiating chondroblast differentiation, and is considered to be critical for chondrogenesis (Akiyama et al., 2002). SOX9 binds to the promoter region of the collagen type II gene (COL2A1) and results in the expression of collagen type II. In the absence of SOX9, blocking at the mesenchymal condensation stage occurs, suggesting that the factor is required for initiation of chondrogenesis (Zhao et al., 1997). Hence, the level of SOX9 gene expression has been considered as a critical marker of chondrogenesis. The combination group showed a relative increase in SOX9 expression when compared to individual growth factors. The TGF $\beta 3+\mathrm{BMP} 2$ group showed maximum expression of SOX9. The increased expression of SOX9 with TGF $\beta 3$ and BMP2 supplementation might have contributed to the increased expression of the collagen type II gene in the constructs supplemented with TGF 33 and BMP2 growth factors.

During skeletal development in the embryonic stage, chondrogenesis precedes endochondral ossification. The mature chondrocytes further differentiate into hypertrophic chondrocytes, undergo calcification of matrix and apoptosis leading to vascular invasion and final replacement of cartilage with bone (Tamamura et al., 2005). Thus, collagen type $\mathrm{X}$ is considered to be a marker for hypertrophy. Collagen type $\mathrm{X}$ expression is up-regulated in all growth factor-supplemented constructs, and addition of BMP2 increased the expression of collagen type $\mathrm{X}$. The results were consistent with previous studies on chondrogenic differentiation of bone marrow and adipose MSCs, which reported the inducing effects of BMP2 on maturation and hypertrophic differentiation of mesenchymal stem cells (Mehlhorn et al., 2007; Toh et al., 2007). However, despite the increased expression levels of type X collagen mRNA in the presence of BMP2, there is a consistent decrease in the collagen type I mRNA expression with all growth factors except when supplemented with TGF $\beta 1$. No significant reduction in proliferation rate is observed, suggesting that apoptosis - which is the next stage beyond cartilage hypertrophy (Gibson, 1998) - has not occurred up to a period of $28 \mathrm{~d}$. Overall, in the results of chondrogenic differentiation of hUCMSC in 3D PVA-PCL scaffold with respect to the expression pattern of chondrogenic markers, i.e. the ratio of collagen II: collagen I:collagen $\mathrm{X}$, the combination of TGF $\beta 3$ and BMP2 is found to promote chondrogenesis.

Members of the TGF beta super family play a central role in the chondrogenesis process. The growth factor interacts with two heteromeric complexes (TGFßRI and TGF $\beta$ RII) or through an additional receptor (TGF $\beta$ RIII/ endoglin), to mount a physiological response leading to chondrogenic differentiation (Goessler et al., 2005). CD105 or endoglin is a cell surface marker that is expressed in high amounts in hUCMSC. This could be the reason for the enhanced chondrogenic response of hUCMSC to TGF $\beta 3$ growth factor. IGF also plays an important role in skeletal development, as indicated by various studies (McQueeney and Dealy, 2001; Steinert et al., 2009). The biological action of IGFs is transduced by the type I tyrosine kinase receptor (IGFIR) that classically activates the mitogen-activated protein kinase/extracellular signalregulated kinase-kinase 1/2 (MEK1/2), extracellular 
signal-regulated kinase 1/2 (Erk1/2), mitogen activated protein kinase (MAPK), and the phosphatidyl inositol-3kinase-Akt (PI3K-Akt) pathways. To avoid the non-specific stimulation of high levels of insulin present in the ITS premix, this study evaluated the biological effect of IGF in the absence of insulin. However, the results suggest that even though IGF and its combination with BMP2 promotes chondrogenesis at the concentration assigned in the present study, its effectiveness in hUCMSC chondrogenesis is inferior to TGF $\beta$ growth factors.

In BMP2 treated constructs, the overall chondrogenic response was very low. Our results correlate with previous reports that BMP2 is osteoinductive rather than chondrogenic (Carlberg et al., 2001). However, it should be noted that BMP2 showed better chondrogenesis when combined with other chondrogenic growth factors. So it could be inferred that the initiation of chondrogenic differentiation by other growth factors is further augmented by BMP2-mediated signalling that resulted in an enhanced chondrogenic response.

The compressive modulus of cell-seeded constructs was assessed to evaluate the biomechanical condition of stem cell-derived cartilage. However, the amount of matrix synthesised during $28 \mathrm{~d}$ of culture was not sufficient to change the bulk mechanical properties of the scaffold and for this reason no significant difference in the compressive modulus of cell-seeded constructs was observed.

In summary, when comparing the effect of soluble growth factors in the in vitro chondrogenesis of human umbilical cord MSCs, a combination of growth factors seems to be effective in maximising the chondrogenic impact as well as simulating the in vivo growth factor milieu rather than single growth factor administration. Based on the above results, it is concluded that the combination of TGF $\beta 3$ and BMP2 promotes better chondrogenic differentiation of hUCMSCs in PVA-PCL scaffolds than the other selected ones. However, it should be considered that the growth factor concentrations used in the present study are based on literature reports on chondrogenic differentiation of other mesenchymal stem cell sources. Since the action of each growth factor depends on its concentration and time point of delivery, the current results could be changed at varying concentrations of growth factors.

The progression from undifferentiated MSC to differentiated cells involves the activation or suppression of certain signalling pathways. These pathways may be specific to one lineage or may be important for the differentiation process in general. To predict signalling pathways active in chondrogenically differentiating MSCs, we examined the known signalling pathways in chondrogenic differentiation, based on existing literature reports. Chondrogenic differentiation of MSCs in vitro mimics that of cartilage development in vivo. Expression markers associated with chondrogenesis have been positively characterised in MSC-derived chondrocytes, including transcription factors (SOX9) and extracellular matrix (ECM) genes (collagen type II, aggrecan and cartilage oligomeric matrix protein). The signalling molecules, including TGF $\beta$, BMP, IGF etc., have also been identified. It has been reported that upon receptor binding, TGF $\beta$ s and BMPs signal through specific intracellular Smad protein and major mitogen-activated protein kinase (MAPK) cascades, initiating the processes that lead to chondrogenic differentiation. As documented in the literature, the main signalling pathway involved in chondrogenic differentiation is the TGF $\beta$ signalling pathway mediated by the Smad proteins (Chen et al., 2012). So the expression of Smad genes were evaluated under different growth factor conditions to understand the molecular mechanism in signalling process of chondrogenic differentiation of hUCMSC.

Smad 1, the substrate for BMP2 signalling molecules, was expressed in all the constructs. However, an upregulated expression when compared to control, i.e. without growth factors was observed in constructs supplemented with BMP2, except in IGF+BMP2-supplemented constructs. The persisting up-regulated expression of Smad 1 genes even after the culture period suggests that the signalling pathway is active under BMP2 supplementation.

Up-regulated expression of Smad 3, which is the substrate for activated TGF beta receptors, was observed in all the growth factor-supplemented constructs, suggesting that active TGF $\beta$ signalling is going on in the culture. TGF $\beta$ receptor I has been shown to cause receptor activated Smad 2/3 activation, amplifying the signals occurring as a result of exogenous TGF $\beta 1$ or TGF $\beta 3$ stimulation. The high binding affinity of TGF $\beta 1$ to TGF $\beta$ receptors might have resulted in increased activation of receptors, which accounts for the increased expression of Smad 3 proteins in TGF $\beta 1$-supplemented conditions.

Other intracellular signalling pathways, such as the MAPK-mediated pathway, have been shown to be activated by TGF $\beta$ in promoting cartilage-specific gene expression (Tuli et al., 2003). In the present study, MAPK is expressed in all the constructs, including the cells not treated with growth factor, suggesting that this pathway is involved in the normal physiological activities of hUCMSC. However, when compared to control significant up-regulation was seen in TGF $\beta 1$-supplemented constructs, suggesting activation of the MAPK pathway by TGF $\beta 1$-mediated signalling.

\section{Conclusion}

Human umbilical cord MSCs can be easily isolated from umbilical cords that are discarded uterine tissues. The multi differentiation and high expansion ability of these stem cells, when cultured in vitro gives them the potential to generate large number of expanded MSCs that could be used for tissue engineering applications. Mesenchymal stem cells interact with numerous microenvironment cues, including adhesion receptors and soluble growth factors, in order to mount a physiologically relevant differentiation process. It could be inferred from this study that the threedimensional cell-cell as well as cell-matrix interactions provided by the PVA-PCL scaffold architecture, along with the appropriate combination of chondrogenic growth factors, TGF $\beta 3+$ BMP2, promotes successful and efficient chondrogenesis of hUCMSC. Previous reports have shown that TGF $\beta 3$ and BMP2 promote chondrogenesis of bone 
marrow stem cells (Mohan et al., 2010; Shen et al., 2008) and both growth factors act by distinct mechanisms to promote in vitro differentiation to cartilage. When used in combination, both the pathways might have been activated and resulted in enhanced chondrogenesis. It could be observed that both the Smad 1 and Smad 3 genes are upregulated in the combination group that might have contributed to enhanced chondrogenesis. Interestingly, smooth muscle differentiation of MSCs by TGF $\beta 1$ (Chen and Lechleider, 2004) might be the reason for the lack of the same phenomenon in TGF $\beta 1$ and BMP2-supplemented constructs. However, we have not conducted any further studies to confirm this explanation by inhibiting the growth factor action by specific antagonists and evaluating its effect. Further studies are also needed to address the effect of these growth factors on chondrogenesis upon sequential supplementation rather than in combination.

\section{Acknowledgements}

The authors acknowledge the Director and Head, BMT Wing, Sree Chithra Tirunal Institute for Medical Sciences and Technology, India for the facilities provided, Dept. of Biotechnology, COE Programme in Tissue Engineering for financial assistance, and Remya Nirmal acknowledges the Indian Council for Medical Research for a SRF fellowship. We wish to confirm that there are no known conflicts of interest associated with this publication and there has been no significant financial support for this work that could have influenced its outcome.

\section{References}

Akiyama H, Chaboissier M-C, Martin JF, Schedl A, De Crombrugghe B (2002) The transcription factor Sox 9 has essential roles in successive steps of the chondrocyte differentiation pathway and is required for expression of Sox5 and Sox6. Genes Dev 16: 2813-2828.

Baksh D, Yao R, Tuan RS (2007) Comparison of proliferative and multilineage differentiation potential of human mesenchymal stem cells derived from umbilical cord and bone marrow. Stem Cells 25: 1384-1392.

Blunk T, Sieminski AL, Gooch KJ (2002) Differential effects of growth factors on tissue-engineered cartilage. Tissue Eng 8: 73-84.

Bonassar LJ, Grodzinsky AJ, Frank EH, Davila SG, Bhaktav NR, Trippel SB (2001) The effect of dynamic compression on the response of articular cartilage to insulin-like growth factor-I. J Orthop Res 19: 1-7.

Carlberg AL, Pucci B, Rallapalli R, Tuan RS, Hall DJ (2001) Efficient chondrogenic differentiation of mesenchymal cells in micromass culture by retroviral gene transfer of BMP-2. Differentiation 67: 128-138.

Chen S, Lechleider RJ (2004) Transforming growth factor- $\beta 1$-induced differentiation of smooth muscle from a neural crest stem cell line. Circ Res 94: 1195-1202.

Chen G, Deng C, Li YP (2012) TGF- $\beta$ and BMP signaling in osteoblast differentiation and bone formation. Int J Biol Sci 8: 272-288.
Ciavarella S, Dammacco F, De Matteo M, Loverro G, Silvestris F (2009) Umbilical cord mesenchymal stem cells: role of regulatory genes in their differentiation to osteoblasts. Stem Cells Dev 18: 1211-1220.

Csaki C, Schneider PRA, Shakibaei M (2008) Mesenchymal stem cells as a potential pool for cartilage tissue engineering. Ann Anat 190: 395-401.

Derfoul A, Perkins GL, Hall DJ, Tuan RS (2006) Glucocorticoids promote chondrogenic differentiation of adult human mesenchymal stem cells by enhancing expression of cartilage extracellular matrix genes. Stem Cells 24: 1487-1495.

Diekman BO, Rowland CR, Lennon DP, Caplan AL, Guilak F (2009) Chondrogenesis of adult stem cells from adipose tissue and bone marrow: Induction by growth factors and cartilage-derived matrix. Tissue Eng Part A 16: $523-533$.

Dominici M, Le Blanc K, Mueller I (2006) Minimal criteria for defining multipotent mesenchymal stromal cells. The International Society for Cellular Therapy position statement. Cytotherapy 8: 315-317.

Dussault AA, Pouliot M (2006) Rapid and simple comparison of messenger RNA levels using real-time PCR. Biol Proced Online 8: 1-10.

Farndale RW, Buttle DJ, Barrett AJ (1986) Improved quantitation and discrimination of sulphated glycosaminoglycans by use of dimethylmethylene blue. Biochim Biophys Acta 883: 173-176.

Fong CY, Subramanian A, Gauthaman LF, Venugopal J, Ramakrishna S, Bongoso A (2010) Human umbilical cord Wharton's jelly stem cells undergo enhanced chondrogenic differentiation when grown on nanofibrous scaffolds and in a sequential two-stage culture medium environment. Stem Cell Rev Rep 8: 195-209.

Gibson G (1998) Active role of chondrocyte apoptosis in endochondral ossification. Microsc Res Tech 43: 191204.

Gong Z, Niklason LE (2008) Small-diameter human vessel wall engineered from bone marrow-derived mesenchymal stem cells (hMSCs). FASEB J 22: 16351648.

Goessler UR, Bugert P, Bieback K, Deml M, Sadick H, Hormann K, Riedel F (2005) In-vitro analysis of the expression of TGF beta - super family-members during chondrogenic differentiation of mesenchymal stem cells and chondrocytes during dedifferentiation in cell culture. Cell Mol Biol Lett 10: 345-362.

Hartmann I, Hollweck T, Haffner S (2009) Umbilical cord tissue-derived mesenchymal stem cells grow best under GMP-compliant culture conditions and maintain their phenotypic and functional properties. J Immunol Methods 363: 80-86.

Heng BC, Cao T, Lee EH (2004) Directing stem cell differentiation into the chondrogenic lineage in vitro. Stem Cells 22: 1152-1167.

Hou T, Xu J, Wu X, Xie Z, Luo F, Zhang Z, Zeng L (2009) Umbilical cord Wharton's jelly: A new potential cell source of mesenchymal stromal cells for bone tissue engineering. Tissue Eng Part A 15: 2325-2334.

$\mathrm{Hu}$ B, Wu Z, Phan SH (2003) Smad3 mediates transforming growth factor-beta-induced alpha-smooth 
muscle actin expression. Am J Resp Cell Mol Biol 29: 397-404.

Karahuseyinoglu S, Cinar O, Kilic E (2007) Biology of stem cells in human umbilical cord stroma: in situ and in vitro surveys. Stem Cells 25: 319-331.

Kuo CK, Li WJ, Mauck RL, Tuan RS (2006) Cartilage tissue engineering: Its potential and uses. Curr Opin Rheumatol 18: 64-69.

Langer R, Tirrell DA (2004) Designing materials for biology and medicine. Nature 428: 487-491.

Longobardi L, O'Rear L, Aakula S, Johnstone B, Shimer K, Chytil A, Horton WA, Moses HL, Spangnoli A (2006) Effect of IGF-I in the chondrogenesis of bone marrow mesenchymal stem cells in the presence or absence of TGF- $\beta$ signaling. J Bone Miner Res 21: 626 -631.

Majumdar Mk, Wang E, Morris EA (2001) BMP-2 and BMP-9 promotes chondrogenic differentiation of human multipotential mesenchymal cells and overcomes the inhibitory effect of IL-1. J Cell Physiol 189: 275-284.

Mayne R (1989) Cartilage collagens. What is their function, and are they involved in articular disease? Arthritis Rheum 32: 241-246.

McQueeney K, Dealy CN (2001) Roles of insulinlike growth factor-I (IGF-I) and IGF-I binding protein-2 (IGFBP2) and -5 (IGFBP5) in developing chick limbs. Growth Horm IGF Res 11: 346-363.

Medvedev S, Shevchenko A, Mazurok N, Zakian S (2008) OCT4 and NANOG are the key genes in the system of pluripotency maintenance in mammalian cells. Russian J Genet 44: 1377-1381.

Mehlhorn A T, Niemeyer P, Kaschte. K, Muller L, Finkenzeller G, Hartl D, Sudkamp N.P, Schmal H. (2007) Differential effects of BMP-2 and TGF- $\beta 1$ on chondrogenic differentiation of adipose derived stem cells. Cell Prolif 40: 809-823.

Mohan N, Nair PD (2008) Polyvinyl alcoholpoly(caprolactone) semi IPN scaffold with implication for cartilage tissue engineering. J Biomed Mater Res Part B 84B: 584-592.

Mohan N, Nair PD (2010) A synthetic scaffold favoring chondrogenic phenotype over a natural scaffold. Tissue Eng Part A 16: 373-378.

Mohan N, Nair PD, Tabata Y (2010) Growth factormediated effects on chondrogenic differentiation of mesenchymal stem cells in 3D semi-IPN poly(vinyl alcohol)-poly(caprolactone) scaffolds. J Biomed Mater Res Part A, 94A: 146-159.

Moreau JE, Chen J, Bramono DS (2005) Growth factor induced fibroblast differentiation from human bone marrow stromal cells in vitro. J Orthop Res 23: 164-174.

Noel D, Gazit D, Bouquet C, Apparailly F, Bony C, Plence P, Millet V, Turgeman G, Perricaudet M, Sany J, Jorgensen C (2004) Short-term BMP-2 expression is sufficient for in vivo osteochondral differentiation of mesenchymal stem cells. Stem Cells 22: 74-85.

Schmitt B, Ringe J, Haupl T (2003) BMP2 initiates chondrogenic lineage development of adult human mesenchymal stem cells in high-density culture. Differentiation 71: 567-577.

Shen B, Wei A, Tao H, Diwan AD, Ma DF (2008) BMP-2 enhances TGF-beta 3 mediated chondrogenic differentiation of human bone marrow multipotent mesenchymal stromal cells in alginate bead culture. Tissue Eng Part A 15: 1311-1320.

Sophia Fox AJ, Bedi A, Rodeo SA (2009) The basic science of articular cartilage: Structure, composition, and function. Sports Health 1: 461-467.

Steinert AF, Palmer GD, Pilapil C, Nöth U, Evans CH, Ghivizzani SC (2009) Enhanced in vitro chondrogenesis of primary mesenchymal stem cells by combined gene transfer. Tissue Eng Part A 15: 1127-1139.

Stoddart MJ, Grad S, Eglin D, Alini M (2008) Cells and biomaterials in cartilage tissue engineering. Regen Med 4: 81-89.

Tamamura Y, Otani T, Kanatani N. Y, Koyama E, Kitagaki J, Toshihisa Komori T, Yamada. Y, Costantini F, Wakisaka S, Pacifici M, Iwamoto M, Enomoto-Iwamoto M (2005) Developmental regulation of $\mathrm{Wnt} / \mathrm{I}^{2}$-Catenin signals is required for growth plate assembly, cartilage integrity, and endochondral ossification. J Biol Chem 280: 19185-19195.

Temenoff JS, Mikos AG (2000) Review: Tissue engineering for regeneration of articular cartilage Mechanical factors affecting cartilage regeneration in vitro. Biomaterials 21: 431-437.

Tipnis S, Viswanathan C, Majumdar AS (2010) Immunosuppressive properties of human umbilical cordderived mesenchymal stem cells: role of B7-H1 and IDO. Immunol Cell Biol 88: 795-806.

Toh WS, Yang Z, Liu H, Heng BC, Lee EH, Cao T (2007) Effects of culture conditions and bone morphogenetic protein 2 on extent of chondrogenesis from human embryonic stem cells. Stem Cells 25: 950-960.

Tuan R, Boland G, Tuli RZ (2003) Adult mesenchymal stem cells and cell-based tissue engineering. Arthritis Res Ther 5: 32-45.

Tuli R, Tuli S, Nandi S, Huang X, Manner PA, Hozack WJ, Danielson KG, Hall DJ, Tuan RS (2003) Transforming growth factor-beta-mediated chondrogenesis of human mesenchymal progenitor cells involves $\mathrm{N}$-cadherin and mitogen-activated protein kinase and Wnt signaling crosstalk. J Biol Chem 278: 41227-41236.

Van der Zande M, Walboomers XF, Briest A, Springer M, Alava JI, Jansen JA (2008) The effect of combined application of TGFbeta-1, BMP-2, and COLLOSS E on the development of bone marrow derived osteoblast-like cells in vitro. J Biomed Mater Res A 86: 788-795.

Wang L, Detamore MS (2009) Insulin -like growth factor-1 improves chondrogenesis of predifferentiated human umbilical cord mesenchymal stromal cells. J Orthop Res 27: 1109-1115.

Wang HS, Hung SC, Peng ST, Huang CC, Wei HM, Guo YJ, Fu YS, Lai MC, Chen CC (2004) Mesenchymal stem cells in the Wharton's jelly of the human umbilical cord. Stem Cells 22: 1330-1337.

Wang L, Seshareddy K, Weiss ML, Detamore MS (2009).Effect of initial seeding density on human umbilical cord mesenchymal stromal cells for fibrocartilage tissue engineering. Tissue Eng Part A 15: 1009-1017.

Zhang W, Green C, Stott NS (2002) Bone morphogenetic protein-2 modulation of chondrogenic differentiation 
in vitro involves gap junction-mediated intercellular communication. J Cell Physiol 193: 233-243.

Zhao L, Detamore M (2010) Chondrogenic differentiation of stem cells in human umbilical cord stroma with PGA and PLLA scaffolds. J Biomed Sci Eng 3: 1041-1049.

Zhao Q, Eberspaecher H, Lefebvre V, De Crombrugghe B (1997) Parallel expression of Sox9 and Col2a1 in cells undergoing chondrogenesis. Dev Dyn 209: 377-386.

\section{Discussion with Reviewer}

Reviewer I: An interesting point of discussion is the benefits and applications of using such umbilical cord MSCs versus other types of progenitor cells.

Authors: Umbilical cord MSCs are derived from a noncontroversial tissue source that can be harvested with non-invasive procedures at low cost. Since umbilical cord MSCs are derived from a clinically discarded source, the problems and ethical concerns surrounding ESCs do not arise. These cells, like bone marrow MSCs, are plastic adherent, express markers of the mesenchymal cells, such as CD10, CD13, CD29, CD44, CD90 and CD105, and lack markers of haematopoietic origin. Compared with other adult sources, which possess age-dependent differentiation and expansion potential, umbilical cord MSCs have high expansion and proliferation ability and multi-differentiation potential that makes them an attractive stem cell source for tissue engineering and other cell-based therapies. Even though additional stem cell niches present in post natal tissues, such as placenta, amniotic fluid etc., are reported, they are largely untested at this early point in their development as a promising cell source for regenerative applications. 